\title{
OPTICAL MONITORING AND FORECASTING SYSTEMS FOR HARMFUL ALGAL BLOOMS: POSSIBILITY OR PIPE DREAM?
}

\author{
Oscar Schofield, Joe Grzymski \\ Coastal Ocean Observation Laboratory, Institute of Marine and Coastal Sciences, Rutgers University, New Brunswick, New Jersey 08901
}

\section{W. Paul Bissett}

Florida Environmental Research Institute, 4807 Bayshore Boulevard, Suite 101, Tampa, Florida 33611

Gary J. Kirkpatrick

Mote Marine Laboratory, 1600 Thompson Parkway, Sarasota, Florida 34236

David F. Millie

Agricultural Research Service, U.S. Department of Agriculture, New Orleans, Louisiana and Mote Marine Laboratory, 1600 Thompson Parkway, Sarasota, Florida 34236

Mark Moline

Department of Biological Sciences, California Polytechnic State University, San Luis Obispo, California 93407

and

Collin S. Roesler

Bigelow Laboratory for Ocean Sciences, West Boothbay Harbor, Maine 04575

Monitoring programs for harmful algal blooms (HABs) are currently reactive and provide little or no means for advance warning. Given this, the development of algal forecasting systems would be of great use because they could guide traditional monitoring programs and provide a proactive means for responding to HABs. Forecasting systems will require near real-time observational capabilities and hydrodynamic/biological models designed to run in the forecast mode. These observational networks must detect and forecast over ecologically relevant spatial/ temporal scales. One solution is to incorporate a multiplatform optical approach utilizing remote sensing and in situ moored technologies. Recent advances in instrumentation and data-assimilative modeling may provide the components necessary for building an algal forecasting system. This review will outline the utility and hurdles of optical approaches in HAB detection and monitoring. In all the approaches, the desired HAB information must be isolated and extracted from the measured bulk optical signals. Examples of strengths and weaknesses of the current approaches to deconvolve the bulk optical properties are illustrated. After the phytoplankton signal has been isolated, species-recognition algorithms will be required, and we demonstrate one approach developed for Gymnodinium breve Davis. Pattern-recognition algorithms will be species-specific, reflecting the acclimation state of the $\mathrm{HAB}$ species of interest.
Field data will provide inputs to optically based ecosystem models, which are fused to the observational networks through data-assimilation methods. Potential model structure and data-assimilation methods are reviewed.

Key index words: bio-optics; forecasting; harmful algal blooms; remote sensing

An early forecasting system "The oyster is unseasonable and unwholesome in all months that have not the letter ' $r$ ' in their name." Henry Buttes from Dyets Dry Dinner, 1599 (The Handbook of Quotations, Classical \& Medieval).

Predicting and monitoring harmful algal blooms (HABs) is central to developing proactive strategies to ameliorate their impact on human health and the economies of coastal communities. As part of these efforts, numerous coastal monitoring programs have been enacted. Monitoring programs have traditionally detected HABs by visual confirmation (water discoloration and fish kills), illness to fish consumers (Carder and Steward 1985, Riley et al. 1989, Pierce et al. 1990), chemical analyses for toxin levels in shellfish samples (Schulman et al. 1990, Trainor and Baden 1990), or mouse bioassays (McFarren et al. 1965). Most of the traditional techniques are labor intensive, which limits the temporal and spatial resolution of the potential monitoring programs. These sampling limitations bias our understanding of harmful taxa and the environmental conditions promoting bloom initiation, maintenance, and se- 


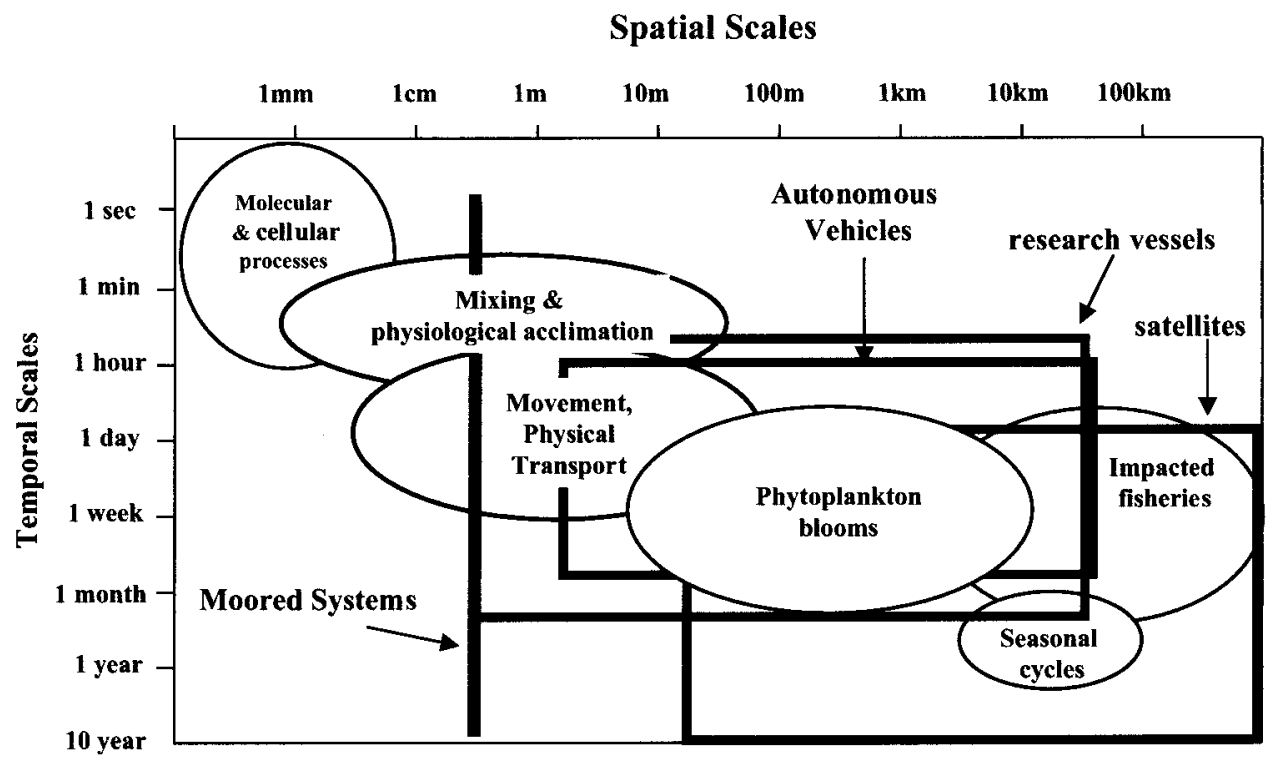

Fig. 1. The relevant temporal and spatial scales for critical processes regulating phytoplankton ecology (circles) and the sampling capabilities of the diverse sampling platforms available (squares). Redrawn and modified from Dickey (1993).

nescence. Developing approaches to characterize the different stages of phytoplankton-bloom dynamics will ultimately require a suite of approaches to provide sufficient sensitivity to detect dilute populations of specific species in mixed phytoplankton communities.

Over the past two decades, oceanographers have developed optical instrumentation that can collect data in a nonintrusive manner [cf. Limnology and Oceanography 1989: vol. 34(8) and Journal of Geophysical Research 1995: vol. 100(C7)]. Optical techniques are amenable to a variety of platforms (satellites, aircrafts, mooring, and profiling instrumentation) allowing researchers to design multiplatform sampling networks capable of collecting data over ecologically relevant scales (Smith et al. 1987, Fig. 1). Many integrated observing systems currently are under development by the oceanographic community. These approaches show much promise in mapping the distribution of phytoplankton and will be useful in monitoring HABs (Cullen et al. 1997). Furthermore, combining optical approaches with ocean forecast systems (Mooers 1999) would potentially provide water-quality managers a means to prepare for anticipated problems. Although promising, optical approaches have been criticized because they provide only bulk composite signals for a water mass, and the signatures for distinct phytoplankton species are difficult to discriminate (Garver et al. 1994).

Recent advances in instrumentation, bio-optical models, and coupled observation network/model systems may offer new tools to tackle these issues. Therefore, in this paper we will focus on approaches that we believe show promise and hope to provide consideration of the strengths and weaknesses of the technologies available as of today. Specifically, our discussion will focus on the strengths and weaknesses of in situ optical data in relation to HABs, examine optically based ecosystem models which utilize in situ field data, and briefly outline the potential of dataassimilation approaches for the study of HABs. Developing a biological ocean forecasting system is a truly interdisciplinary effort, and a comprehensive review of all the pertinent aspects is beyond a single manuscript; therefore, we have focused our discussion on those approaches with which we are familiar. Given this, we recognize that our discussion may have omitted approaches that might be central to any future forecasting system. For this discussion, we will omit optical detection of phycobilin-containing HABs, such as cyanobacteria, and will focus primarily on chlorophyll $a$ and chlorophyll $c$-containing algae. Whenever possible, field data will be used to illustrate both the strengths and weaknesses of these methods. The majority of the data presented was collected in the Gulf of Mexico as part of a multi-institution effort (http://www.fmri.usf.edu/ecohab/) that focused on defining the ecology of the dinoflagellate Gymnodinium breve Davis. More detailed description of the data will be provided in forthcoming manuscripts, the data here is used to only illustrate potential strengths and shortcomings. Finally a complete description of the uses of hydrological optics to study phytoplankton is well beyond the scope of a single paper. For a more complete treatment of the subject, there are a number of excellent synthetic texts available (Kirk 1994, Mobley 1994, Bukata et al. 1995).

\section{IN SITU OPTICAL MEASUREMENTS}

Significant effort over the last decade has focused on developing techniques to measure the spectral dependency of in situ inherent optical properties (IOPs). The advantage of the IOPs is that they depend only on the medium and are independent of the ambient light field. This makes them easier to 

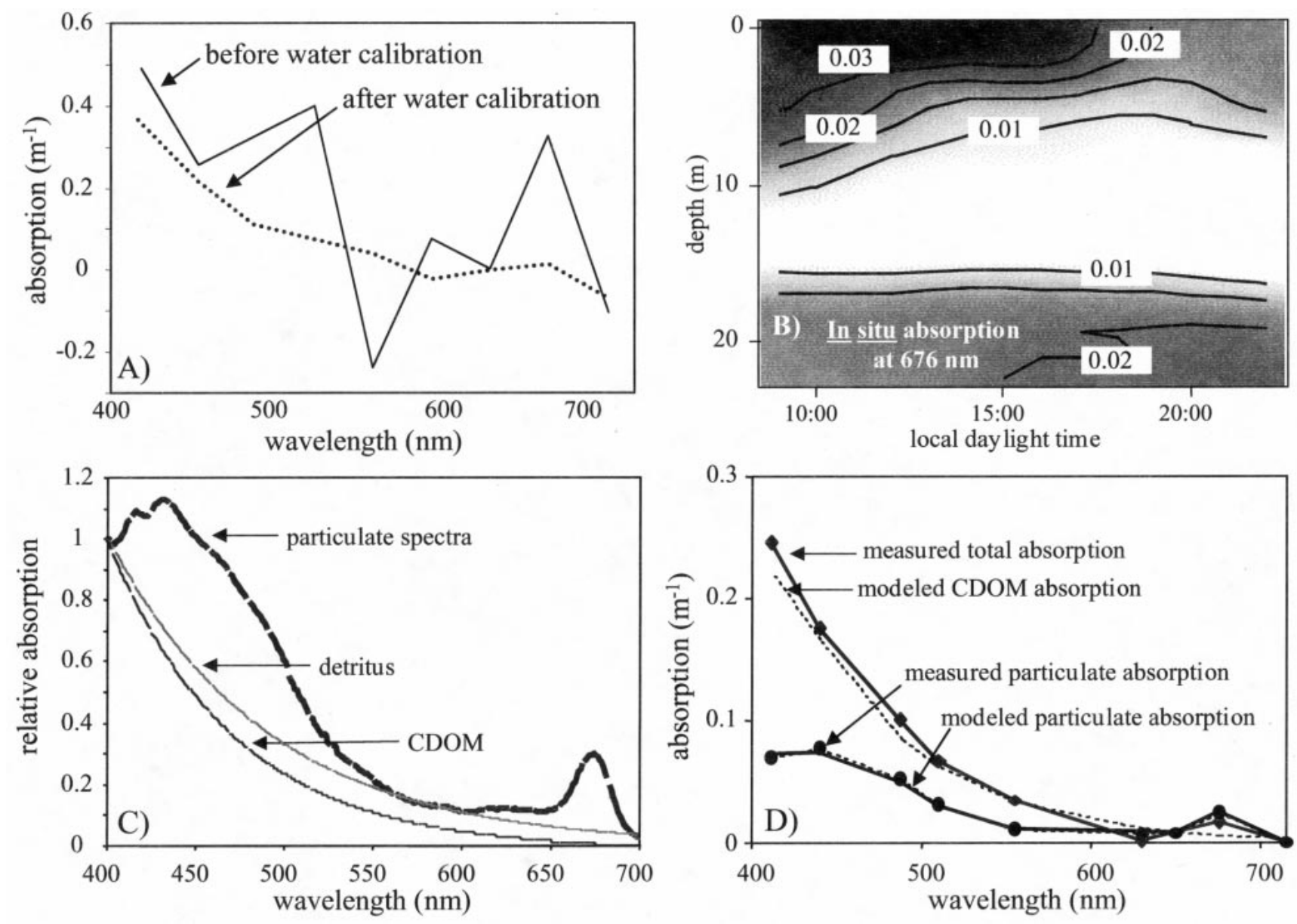

FIG. 2. Examples of the utility of absorption data collected with a WetLabs Inc. AC-9 nine-wavelength absorption-attenuation meter. Data was collected aboard the OSV Anderson from 25 to 31 August 1997 in the Gulf of Mexico. The data represents a subset of a time series study which consisted of hydrographic/optical profiles and discrete water samples analyzed for cell counts, phytoplankton pigmentation measurements, total, dissolved, and methanol-extracted particulate absorption. The study focused on a Gymnodinium breve bloom, which was encountered off Apalachicola Florida. The AC-9 was factory calibrated a few months before the cruise. Manufacturer-recommended protocols were employed to track instrument calibration by filtered air and double-distilled $0.2-\mu \mathrm{m}$ filtered water throughout the cruise. The optical instruments were mounted into a modified sea cage, which had a bottom support and loose clamps in order to minimize torsion, which can affect instrument performance. (A) The difference between absorption spectra before and after a cleanwater calibration for the AC-9 instrument. There is a large discrepancy between the spectra despite the fact that the instrument was factory-calibrated months before the cruise. Given this, daily water calibrations are highly recommended. (B) After a clean-water correction, the total absorption at $676 \mathrm{~nm}$ measured during the Anderson cruise. The interpolated image was constructed from 10 discrete profiles collected over a $20 \mathrm{~h}$ period. High values in surface waters correlated with a monospecific G. breve population. The high values at depth are below the thermocline and consist of a mixed chromophyte community. (C) Representative relative spectra (particulate, detritus, and CDOM) used to deconvolve the bulk absorption measured during the cruise. (D) An example of deconvolving total absorption measured by an AC-9. The lines with symbols represent measured quantities. The diamonds represent the total absorption measured by the AC-9 in the surface G. breve bloom. Circles represent particulate absorption measured with a ship-based spectrophometer for the surface $G$. breve bloom. The dotted lines represent the estimated CDOM and particulate absorption using a standard inversion algorithm and the spectra presented in C.

interpret and allows for the partitioning of bulk optical properties into the individual components (e.g. water, dissolved organic matter, phytoplankton, detritus, sediment, etc.). Some IOPs relevant to phytoplankton studies include absorption, attenuation, and scattering. Recently in situ spectral absorption and attenuation meters have become commercially available and can provide robust measurements of absorption/attenuation (and thus scattering) at numerous wavelengths of light (currently up to 100 wavelengths) (Zaneveld et al. 1994, Pegau et al.
1995). These instruments, while becoming increasingly user friendly, do require careful attention when it comes to calibration and maintenance, which if ignored can compromise the spectra (Fig. 2A; Pegau et al. 1995).

Absorption. Data from submersible instrumentation reflect bulk absorption, which represents the additive absorption of the specific in situ constituents (Fig. 2C). The instrument signal can be deconvolved into the contributions by all absorption components according to: 


$$
a(\lambda)=\sum_{i=1}^{n} x_{i} \cdot a_{i}(\lambda)
$$

where $a_{i}(\lambda)$ refers to absorption at wavelength $\lambda$ for component $x$. Because the instruments are calibrated relative to pure water, the bulk signal can be operationally separated into particulate and dissolved material:

$$
a_{\text {total }}-a_{\text {water }}=a_{\text {dissolved }}+a_{\text {particulates }}
$$

and the particulate material can be further partitioned into functional groups:

$$
a_{\text {particulates }}=a_{\text {phytoplankton }}+a_{\text {sediments }}+a_{\text {detritus }}
$$

Particulate absorption. Given equation 3, deriving the estimates of particulate absorption requires inversion algorithms to extract the particulate signature from other constituents that often dominate the bulk optical properties in coastal waters (Morrow et al. 1989, Roesler et al. 1989, Bricaud and Stramski 1990, Gallegos et al. 1990, Cleveland and Perry 1994, Roesler and Zaneveld 1994). These inversion techniques are based on modeling the volumetric absorption using generalized absorption spectral shapes for one or more of the individual absorbing components or using absorption ratios of different wavelengths that vary in a predictable way according to the components present. The first step in deriving a particulate spectra, involves modeling or measuring the absorption due to Colored Dissolved Organic Matter (CDOM) so it can be removed from the bulk absorption spectra. The CDOM absorption (or gelbstoff) can be described as (Kalle 1966, Bricaud et al. 1981, Green and Blough 1994, CDOM spectra in Fig. 2C),

$$
a_{\mathrm{CDOM}}(\lambda)=a_{\mathrm{CDOM}}\left(\lambda_{440 \mathrm{~nm}}\right) \exp \left[-S \cdot\left(\lambda-\lambda_{440 \mathrm{~nm}}\right)\right]
$$

The exponential " $S$ " parameter $\left(\mathrm{nm}^{-1}\right)$ depends on the composition of the CDOM present and can vary over $40 \%$ with values in marine systems ranging from 0.011 to 0.019 (Carder et al. 1989, Roesler et al. 1989), but many freshwater systems, estuaries, and enclosed oceans exhibit even greater variability in $S$ (Jerlov 1976, Kirk 1977). The exponential coefficient also depends upon the wavelength range; generally the value increases as the range extends into the ultraviolet wavelengths. Given a value for $S$ and some idealized absorption spectrum for particulates (average spectral shape from independent data sets, see Fig. 2C), the measured bulk absorption spectrum (Fig. 2D) can be deconvolved into volumetric particulate and CDOM absorption using iterative curve fitting procedures. This technique can provide accurate estimates of particulate absorption (Fig. 2D; $R^{2}=0.88$ between measured and predicted absorption for larger unpublished Gulf of Mexico database). The accuracy of these techniques vary significantly with the chosen value of $S$. This sensitivity is likely due to the influence of tripton or detritus which also displays an exponential absorp- tion coefficient, albeit with a flatter slope (Roesler et al. 1989). Thus, a steeper $S$ can be indicative of the dominance by CDOM, whereas a lower $S$ value indicates potential dominance of particulate organic material. Although these techniques are promising, they will require parameterization of the $S$ value and some generalized absorption data tailored to the specific study site. Given this, collecting spectral libraries of the absorption characteristics in the field remains of paramount importance.

Another useful approach that circumvents the assumption of an idealized wavelength dependency for the total absorption and CDOM is based on making in situ measurements with and without $0.2-\mu \mathrm{m}$ filters on the intakes of the instruments (Boss et al. 1998, Roesler 1998, Schofield et al. 1999). The resulting bulk and dissolved spectra can be used to derive particulate absorption with no a priori assumptions about its wavelength dependency (Fig. 3A). An example of a particulate spectrum derived using this approach is presented for a phytoplankton bloom encountered in the coastal waters off New Jersey. The particulate spectrum exhibited a blue to red ratio of 2.5 that is representative of phytoplankton (Prézelin and Boczar 1986) (Fig. 3A), and CDOM showed little absorption in the red wavelengths of light with absorption increasing exponentially with decreasing wavelength (Fig. 3A). The high absorption at $715 \mathrm{~nm}$ and high absorption at $414 \mathrm{~nm}$ reflects the significant presence of detritus and sediment, which emphasizes that this technique provides a particulate spectrum that can represent many constituents (eq. 3). If refined, these techniques offer the potential to generate continuous maps of particulate absorption both as a function of depth and wavelength (Fig. 3B). Furthermore, these approaches are quite amenable for shipboard applications and do not require assumptions about $S$ or some idealized absorption spectra. One potential source of data biasing may be induced by changes in the flow rate of water through the filtered instrument compared to the unfiltered one causing apparent differences in the depth of features. A second source of biasing occurs with differential filter clogging which causes sequential restriction in the nominal "size" of the CDOM that passed through the absorption meter. Unless in situ filter replacement is used, this approach may not be optimal for moored applications

Phytoplankton spectra. Once a particulate spectrum has been derived, it must be deconvolved into the respective absorption of phytoplankton, detritus, and, if necessary, sediments. A series of different models and approaches have been developed to separate algal and nonalgal absorption from each other. The detrital-absorption spectrum can be approximated using an exponential function similar to equation 4; however, the $S$ value is lower than that of CDOM (exponential coefficient for a reference wavelength at $400 \mathrm{~nm}$ ranges from 0.006 to 0.014 

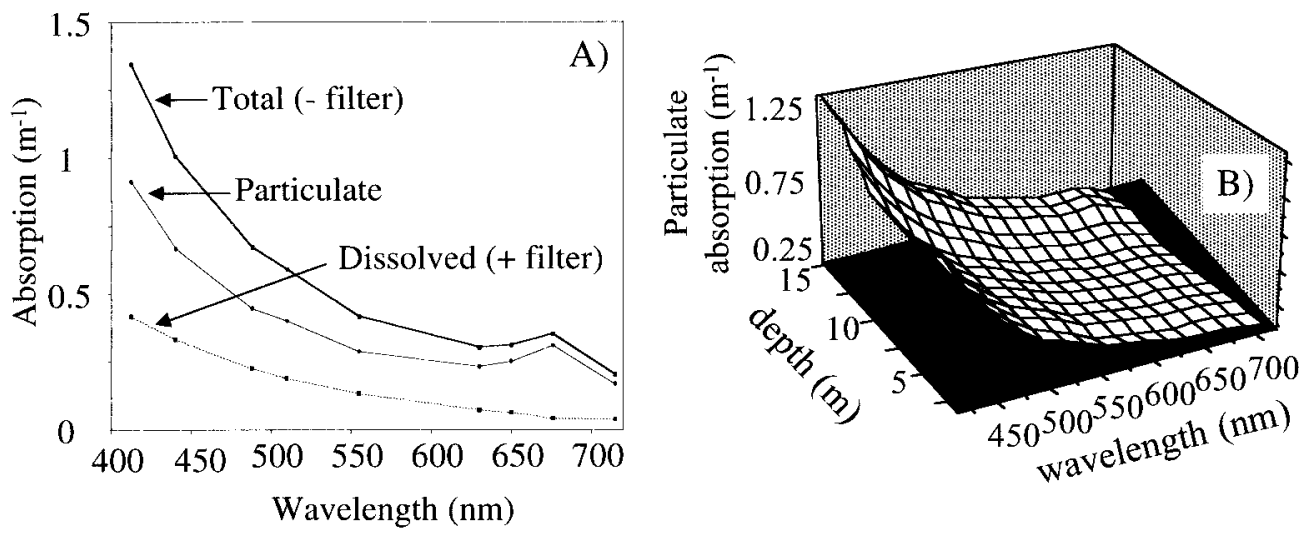

Fig. 3. (A) A representative set of repetitive measurements with and without a $0.2-\mu \mathrm{m}$ filter on the AC-9 to provide estimates of the dissolved and total absorption at the depth of the thermocline off the coast of New Jersey on 24 July 1998. Again, manufacturerrecommended protocols for the AC-9 were used. The particulate spectra (resembling phytoplankton absorption) were derived by subtracting the dissolved from the total absorption and the resulting spectra. (B) The derived particulate absorption spectra as a function of depth for a station off the coast of New Jersey on 24 July 1998.

$\mathrm{nm}^{-1}$; Roesler et al. 1989). Often, approaches have exploited this and the observed low variance in distinct wavelength ratios in phytoplankton absorption to separate algal and nonalgal spectra (Bricuad and Stramski 1990). Other approaches utilize multiple linear (Morrow et al. 1989) or nonlinear Gaussianbased regression techniques (Hoepffner and Sathyendranath 1993). The accuracy of these techniques can vary with location (Varela et al. 1998); therefore it is recommended that initial efforts focus on developing criteria for determining which technique is appropriate for a given field site (Varela et al. 1998). Unfortunately for HAB-specific studies, the variance between the measured and derived spectrum can be noisy or so generalized that it compromises the utility of phytoplankton species identification algorithms (see below). Given this, separating the phytoplankton absorption from the particulate spectrum will be a central problem for $\mathrm{HAB}$ applications.

Species identification. Assuming that a phytoplankton absorption spectrum can be derived from a bulk optical measurement, techniques for delineating the presence and quantity of HAB species in a heterogeneous phytoplankton community are required. Delineation of a particular species can be successful only if the species represents a significant fraction of the overall phytoplankton biomass and/or if it has discriminating features in the cellular optical properties. Differences in the absorption properties between algae can be due to either unique pigments (Jefferey et al. 1997) and/or the light acclimation state associated with the ecological niche occupied by the HAB species.

Laboratory work suggests that partial discrimination of algal species from cellular absorption is possible. For example, Johnsen et al. (1994), using stepwise discriminant analyses to classify absorption spectra among 31 bloom-forming phytoplankton (representing the four main groups of phytoplankton with respect to accessory chlorophylls; that is, chlorophyll $b$, chlorophyll $c_{1}$, and/or $c_{2}$, chlorophyll $c_{3}$, and no accessory chlorophyll), differentiated toxic chlorophyll $c_{3}-$ containing dinoflagellates and prymnesiophytes from taxa not having this pigment. However, problematic and toxic taxa could not be further separated from other chlorophyll $c_{3}$-containing taxa because of the similarities among absorption spectra. Millie et al. (1997) also utilized stepwise discriminant analyses to differentiate mean-normalized absorption spectra for laboratory cultures of $G$. breve from absorption spectra of a diatom, a prasinophyte, and peridinin-containing dinoflagellates. Therefore, absorption sometimes may provide enough information to distinguish among absorption spectra between phylogenetic groups, and potentially taxa. However, wavelengths delineated by the stepwise techniques were wavelengths associated with the accessory carotenoids. This is problematic as the relative absorption in green, yellow, and orange wavelengths where the carotenoids absorb light is much less when compared to the absorption by chlorophyll in the blue and red wavelengths of light. Furthermore, the absorption attributable to unique accessory pigments is difficult to discern because of the dampening of the shoulders on absorption spectra from pigment packaging effects (Duysens 1956, Morel and Bricaud 1986). In addition, the spectral dependency in the absorption properties of marine chlorophyll c-containing algae exhibits little variability among taxa (Roesler et al. 1989, Garver et al. 1994, Johnsen et al. 1994).

In order to maximize the minor inflections in spectral absorption, fourth-derivative analysis (Butler and Hopkins 1970) has been used to resolve the positions of absorption maxima attributable to specific photosynthetic pigments (Bidigare et al. 1989, Smith and Alberte 1994, Millie et al. 1995). Millie et al. (1997) combined derivative analysis with a similarity index to detect the quantity of $G$. breve for mixed laboratory phytoplankton cultures (Fig. 4A, B). In brief, fourth-derivative spectra initially were 

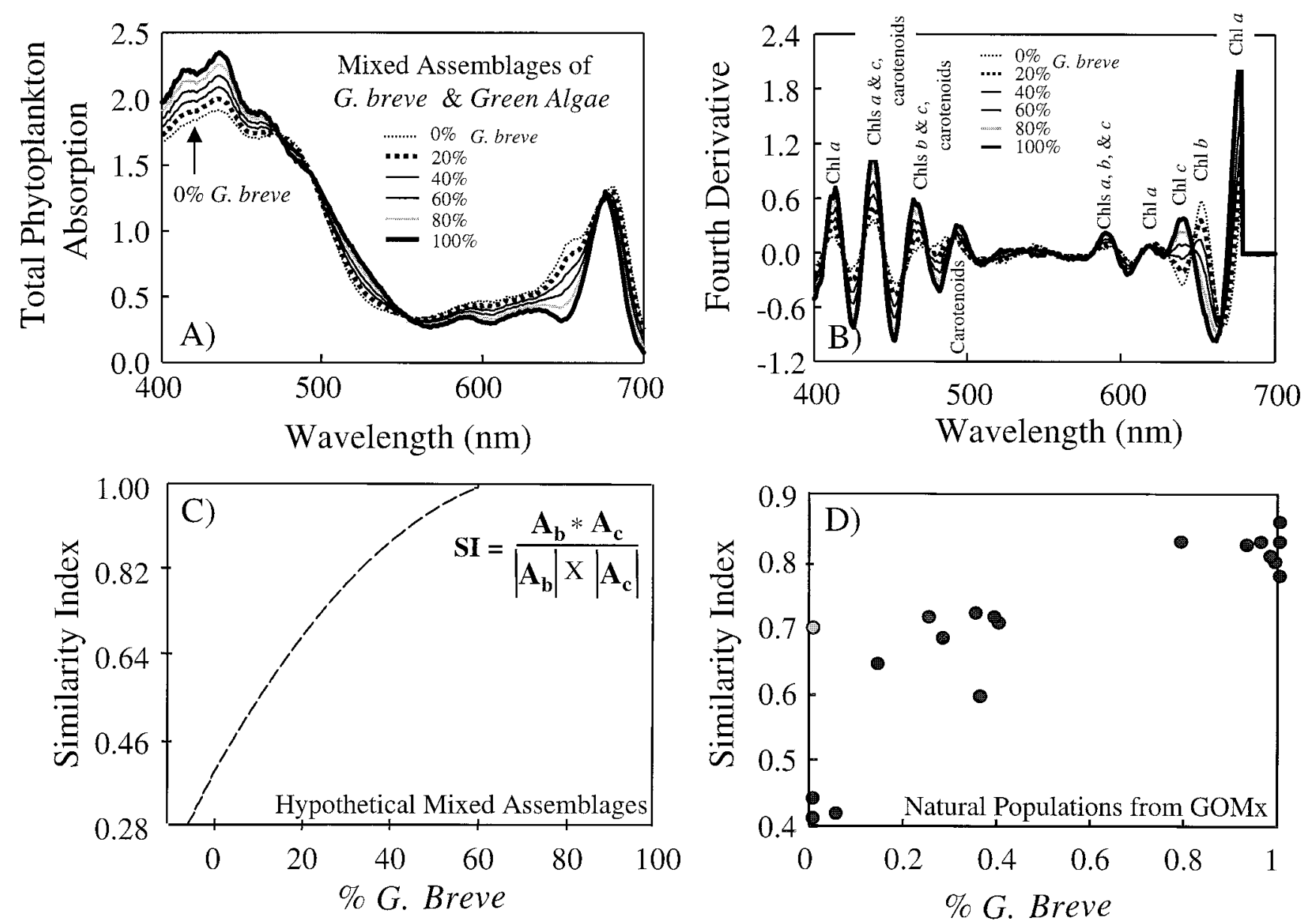

FIg. 4. (A) Absorption for a hypothetical mixed assemblage of Dunaliella tertiolecta and Gymnodinium breve. The individual spectra reflect various proportions of the dinoflagellate and green algae ranging from $0 \%$ to $100 \%$ G. breve (redrawn from Millie et al. 1997). (B) The fourth-derivative spectra for the mixed assemblage spectra presented in A. The individual pigments associated with the specific shoulders in the derivative spectra are delineated (redrawn from Millie et al. 1997). (C) The relationship between the similarity index (eq. 6) versus the relative proportion of $G$. breve for hypothetical mixed assemblages. (D) Similarity-index values associated with natural mixed phytoplankton population encountered in the Gulf of Mexico (Fig. 2B). This dinoflagellate is the only species of phytoplankton in the eastern Gulf of Mexico observed to contain the pigment gyroxanthin-diester and it appears in constant proportion to cellular chlorophyll $a$ in $G$. breve. Quantifying gyroxanthin-diester and chlorophyll $a$ allowed to estimate the fraction of the chlorophyll biomass in mixed populations associated with $G$. breve. Particulate absorption spectra were measured using the quantitative filter technique (QFT) (Kiefer and Soohoo 1982). Sample and reference filters were placed directly in front of the detector windows of a scanning dual-beam spectrophotometer (DMS80, Varian) to minimize scattering loss. Reference spectra for this analysis were collected from a monospecific bloom of G. breve. The data compilation represents samples collected over the course of the year in diverse locations in the Gulf of Mexico. The open circle indicates an estuarine bloom of Cryptoperidinium which has a similar pigment complement but is not found in marine waters associated with $G$. breve.

computed for mean normalized absorption spectra. The spectral similarity index was determined by computing the angle between the vectors comprising the fourth-derivative spectra of a standard $G$. breve sample from the laboratory and an "unknown" mixed assemblage of phytoplankton as:

$$
S I=\left[\frac{A_{s t d} \cdot A_{u n k}}{\left|A_{s t d}\right| \times\left|A_{u n k}\right|}\right]
$$

where $A_{\text {std }}$ and $A_{\text {unk }}$ are the fourth-derivative spectra for $G$. breve and the unknown samples respectively, ' $'$ ' is the vector dot-product operator, and $|A|$ is the vector magnitude operator. This approach showed promise in delineating the presence of $G$. breve for hypothetical mixed assemblages in the lab (Fig. 4C). More recently this approach has been applied to natural mixed assemblages of $G$. breve within the Gulf of Mexico. In this field database, G. breve contributed between zero to $100 \%$ of the measured chlorophyll $a$. Results for these natural mixed populations (Fig. 4D) supported the laboratory findings of Millie et al. (1997) that the absorption due to $G$. breve may be detectable using the derivative/similarity-index approach (Kirkpatrick et al. 1999).

Gymnodinium breve contains the unique chemotaxonomic carotenoid gyroxanthin-diester (Millie et al. 1995); however this accessory pigment does not have unique absorption properties and is not responsible for imparting $G$. breve's unique absorption 

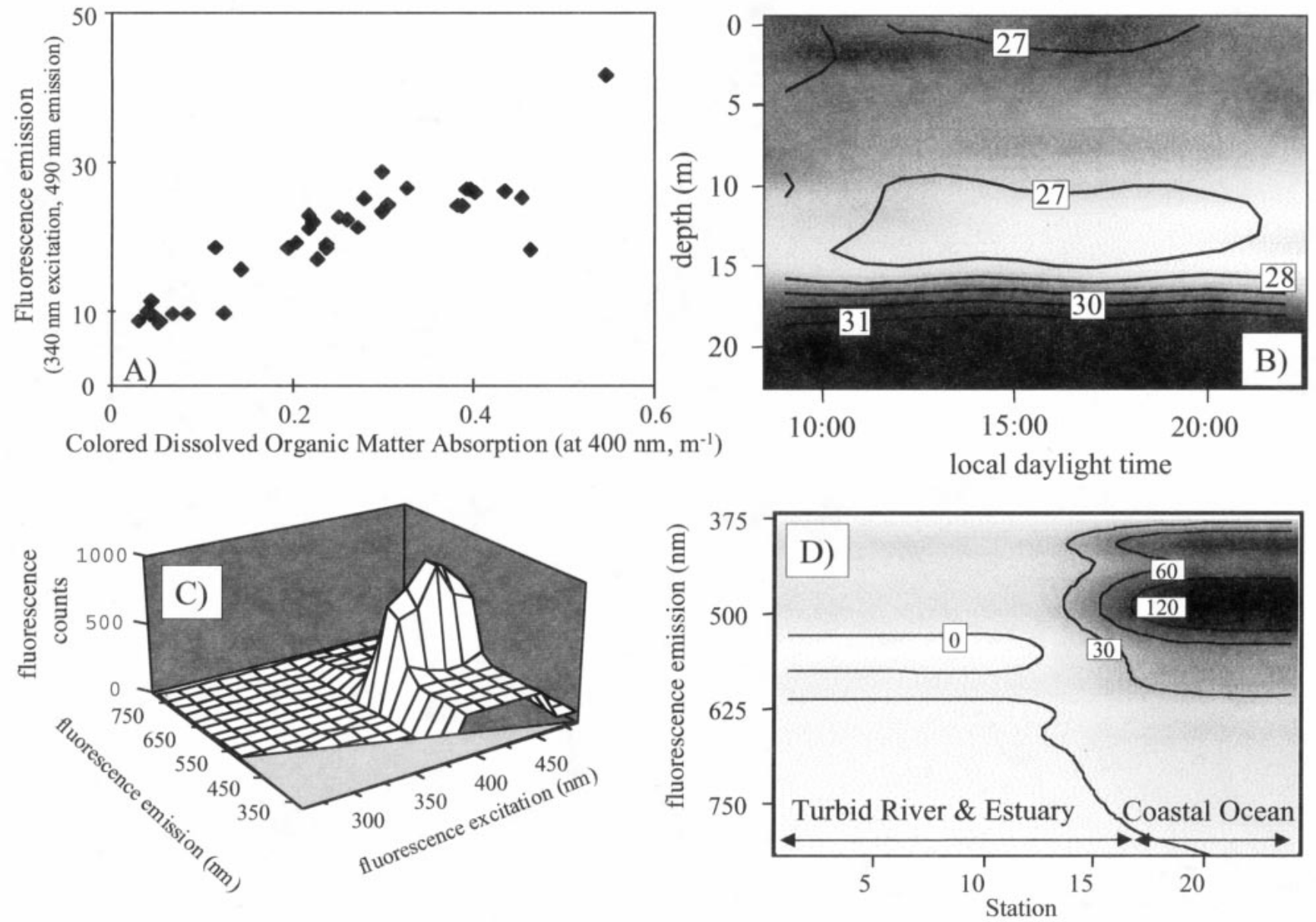

FIG. 5. (A) Scatter plot of CDOM absorption measured at $400 \mathrm{~nm}$ and the CDOM fluorescence (340 nm excitation, $490 \mathrm{~nm}$ emission, fluorescence counts/time, not relative fluorescence units) as measured with the Wetlabs Inc. submersible fixed-wavelength spectrofluorometer (SAFIRE). Data were collected during the OSV Anderson cruise. (B) The depth variability in CDOM fluorescence emission at 550 $\mathrm{nm}$ induced with $340 \mathrm{~nm}$ excitation light. (C) Spectral-fluorescence excitation and emission surface contour plot as measured with the SAFIRE for estuarine waters affected by both the Gulf of Mexico and the Suwannee river. (D) A contour plot for the spectral absorption and fluorescence emission during a transect that began "way up" on the Suwannee River and proceeded out into the Gulf of Mexico. The transition between the Suwannee and the Gulf occurred around station 15, which was marked by a 5-fold increase in water clarity. Within the Suwannee river, CDOM fluorescence was close to zero despite being a blackwater river loaded with humic and fulvic acids. The high concentration of humic and fulvic acids resulted in the absorption of the fluorescence excitation energy before light could reach the fluorescence emission detectors in the instrument flow tubes. This problem was not present within the marsh-transitional waters, coastal, and offshore waters where UV and visible CDOM fluorescence was detectable. This illustrates the need to optimize instrumentation to specific characteristics of the study site.

properties. A possible hypothesis is that the unique absorption property in $G$. breve is a physiological reflection of its ecological niche. Gymnodinium breve is negatively geotactic (Kamykowski et al. 1998) and positively phototactic (Steidinger 1975, Heil 1986, Kamykowski et al. 1998), which results in cells concentrating (as large as $1 \times 10^{8}$ cells $\cdot \mathrm{L}^{-1}$ ) at the airsea interface. Cells therefore must cope with high irradiances (ultraviolet and visible) which results in distinct photoacclimation responses to minimize potential light-induced damage. This hypothesis however is problematic given that cultures of $G$. breve have not been grown in the laboratory under realistically high light (HL) levels, and therefore a "true" reference has yet to be collected; however, laboratory cultures of $G$. breve have been grown at light-saturating levels (500 $\mu \mathrm{mol}$ photons $\left.\cdot \mathrm{m}^{-2} \cdot \mathrm{s}^{-1}\right)$ at least a factor of 4 less than light at the sea surface at local noon and do seem to resemble the absorption spectra collected for natural populations in the field. This might explain why the laboratory based reference spectra seem to be effective for field populations. Assuming that the absorption spectra for cells grown at $500 \mu \mathrm{mol}$ photons $\cdot \mathrm{m}^{-2} \cdot \mathrm{s}^{-1}$ is appropriate, we hypothesize that these photoacclimation responses give $G$. breve its unique absorption properties as cells selectively alter pigment levels leading to absorption spectra distinct from the other species present in the Gulf of Mexico. This does not imply that other algae are incapable of achieving similar absorption characteristics, but simply indicates the greater probability of finding $G$. breve in a HL-accli- 


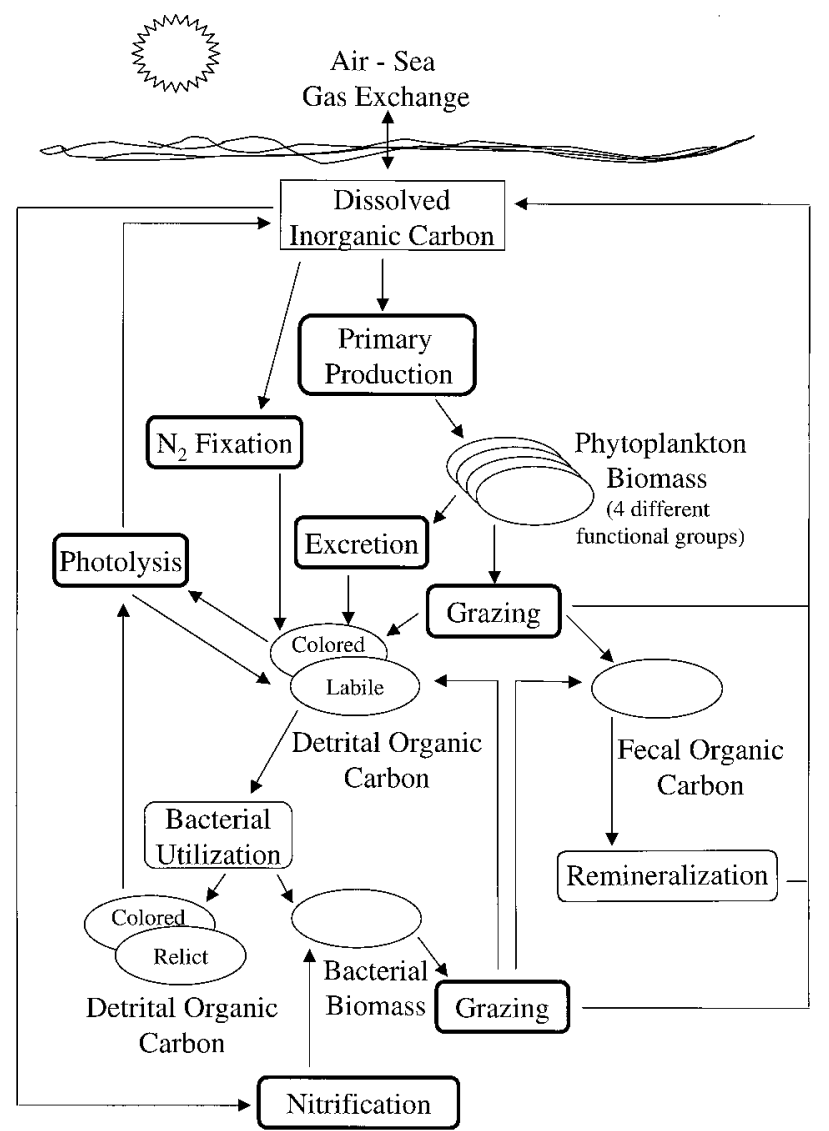

FIG. 6. The ecological and bio-optical interactions in the EcoSim 1.0 model. Squares outlined with bold lines represent optically active processes (i.e. those processes mediated by spectral light). Ovals represent optically active constituents (i.e. those constituents that modify the water column light field). mated state. This feature may be applicable to other $\mathrm{HAB}$ species that often exhibit high growth rates and tolerance to bright light (Carlson and Tindall 1985, Johnsen and Sakshaug 1993). This HL environment also results in enhanced cellular concentrations of UV absorbing compounds (Vernet et al. 1989). Recognizing this, Kahru and Mitchell (1998) increased the sensitivity-discrimination techniques for HABs by extending their measurements into the ultraviolet-A wavelengths of light. Unfortunately, laboratory cultures of $G$. breve cannot be maintained at realistic HL levels found in nature, therefore laboratory HL adapatation is necessary.

Other vector-based, spectral optical-recognition applications have been developed for signal analyses and may provide alternative pattern-recognition tools for phytoplankton optical signatures. These approaches can be combined with other multivariate methods (e.g. neural networks; Lawrence 1994) to enhance the sensitivity of species identification. Future research should focus on the sensitivity of these pattern-recognition approaches and whether newly developed hyperspectral instruments will provide the required input data for species-identification algorithms. Despite promise, several problems remain. Field measurements of absorption in situ (for example, the Histar absorption-attenuation meter, Wetlabs, Inc., Philmoth, Oregon, is commercially available) and deck-board using a spectrophotometer are often noisy. This noise is magnified through analysis/transformation techniques such as the fourth derivative; therefore, improving the signal to noise for in situ optical sensors is important. Furthermore, some of these techniques (like derivative spectra) will require hyperspectral (1-3 $\mathrm{nm}$ resolu-

TABLE 1. Ocean color satellites which will be available in the coming years and the respective satellite characteristics. The delayed resolution specifies the data resolution if data is distributed through the individual federal and international agencies. Real-time resolution is the resolution of the satellite through direct broadcast from the satellite.

\begin{tabular}{|c|c|c|c|c|c|c|}
\hline Satellite (sensor) & Country, no. of channels & Data rate $(\mathrm{mb} / \mathrm{sec})$ & Delayed resolution (m) & Real-time resolution (m) & Revist time (days) & $\begin{array}{c}\text { Operational } \\
\text { (launch date) }\end{array}$ \\
\hline NEMO & U.S.A, & & & & & \\
\hline COIS & 240 & 150 & $30-60$ & $30-60$ & 2.5 & 1999 \\
\hline EOS AM1 & U.S.A, & & & & & \\
\hline MODIS & 2 & & $\mathrm{n} / \mathrm{a}$ & 250 & & \\
\hline MODIS & 5 & & $\mathrm{n} / \mathrm{a}$ & 500 & & \\
\hline MODIS & 29 & 13 & $\mathrm{n} / \mathrm{a}$ & 1000 & 2 & 1999 \\
\hline EOS PM1 & U.S.A, & & & & & \\
\hline MODIS & 2 & & $\mathrm{n} / \mathrm{a}$ & 250 & & \\
\hline MODIS & 5 & & $\mathrm{n} / \mathrm{a}$ & 500 & & \\
\hline MODIS & 29 & 13 & $\mathrm{n} / \mathrm{a}$ & 1000 & 2 & 2000 \\
\hline EO-1 & U.S.A, & & & & & \\
\hline ALI & 10 & & 250 & 30 & & \\
\hline HYPERION & 256 & 105 & 250 & 30 & 16 (tiltable) & Dec. 1999 \\
\hline HY-1 & China, & & & & & \\
\hline COCTS & 10 & & 4000 & 1000 & 2 & \\
\hline CZI & 4 & 5.4 & 4000 & 250 & 6 & 2000 \\
\hline IRS-P4 & India, & & & & & \\
\hline OCM & 8 & 10.4 & 1800 & 360 & 2 & 1999 \\
\hline ADEOS-2 & Japan, & & & & & \\
\hline GLI & 6 & & 1000 & 250 & & \\
\hline GLI & 30 & 6 & 1000 & 1000 & 2 & 2000 \\
\hline
\end{tabular}


TABLE 2. Definitions for the EcoSim model variables and parameters.

\begin{tabular}{|c|c|c|}
\hline Definition & Symbol & Units \\
\hline Total absorption coefficient & $a_{\mathrm{t}}(\lambda, z)$ & $\mathrm{m}^{-1}$ \\
\hline Water absorption coefficient & $a_{\mathrm{w}}(\lambda, z)$ & $\mathrm{m}^{-1}$ \\
\hline Living biomass absorption coefficient & $a_{\mathrm{ph}(t)}(\lambda, z)$ & $\mathrm{m}^{-1}$ \\
\hline Total colored degradational matter absorption coefficient & $a_{\mathrm{CDOM}}(\lambda, z)$ & $\mathrm{m}^{-1}$ \\
\hline Labile colored dissolved organic carbon absorption coefficient & $a_{\mathrm{CDOC}_{1}}(\lambda, z)$ & $\mathrm{m}^{-1}$ \\
\hline Relict colored dissolved organic carbon absorption coefficient & $a_{\mathrm{CDOC}_{2}}(\lambda, z)$ & $\mathrm{m}^{-1}$ \\
\hline Weight-specific absorption of individual pigments & $a_{\mathrm{pig}}^{*}(\lambda, z)$ & $\mathrm{m}^{2} \cdot \mathrm{mg}^{-1}$ \\
\hline Weight-specific absorption of $\mathrm{CDOC}_{1}$ at $410 \mathrm{~nm}$ & $a_{\mathrm{CDOC} 1}^{*}(410)$ & $m^{2} \cdot g^{-1}$ \\
\hline Weight-specific absorption of $\mathrm{CDOC}_{2}$ at $410 \mathrm{~nm}$ & $a_{\mathrm{CDOC} 2}^{*}(410)$ & $\mathrm{m}^{2} \cdot \mathrm{g}^{-1}$ \\
\hline Total backscattering coefficient & $b_{\mathrm{bt}}(\lambda, z)$ & $\mathrm{m}^{-1}$ \\
\hline Scattering coefficient of water & $b_{\mathrm{w}}(\lambda, z)$ & $m^{-1}$ \\
\hline Scattering coefficient of particulates & $b_{\mathrm{p}}(\lambda, z)$ & $\mathrm{m}^{-1}$ \\
\hline Backwards proportion of water scattered photons & $\sim b_{\mathrm{bw}}$ & Unitless \\
\hline Backwards proportion of particulate scattered photons & $\sim b_{\mathrm{bp}}(\lambda, z)$ & Unitless \\
\hline Total colored degradational matter & CDOM & $\mu \mathrm{M} \mathrm{C}$ or $\mu \mathrm{g} \mathrm{C} \mathrm{L}^{-1}$ \\
\hline Labile colored dissolved organic carbon & $\mathrm{CDOC}_{1}$ & $\mu \mathrm{M} \mathrm{C}$ or $\mu \mathrm{g} \mathrm{C} \mathrm{L} \mathrm{L}^{-1}$ \\
\hline Relict colored dissolved organic carbon & $\mathrm{CDOC}_{2}$ & $\mu \mathrm{M} \mathrm{C}$ or $\mu g \mathrm{C} \mathrm{L}^{-1}$ \\
\hline Direct downwelling irradiance just beneath the surface & $E_{\text {dir }}\left(\lambda, 0^{-}\right)$ & $\mu \mathrm{mol}$ quanta $\mathrm{m}^{-2} \cdot \mathrm{s}^{-1} \cdot \mathrm{nm}^{-1}$ \\
\hline Diffuse downwelling irradiance just beneath the surface & $E_{\text {dif }}\left(1,0^{-}\right)$ & $\mu \mathrm{mol}$ quanta $\mathrm{m}^{-2} \cdot \mathrm{s}^{-1} \cdot \mathrm{nm}^{-1}$ \\
\hline Downwelling irradiance & $E_{\mathrm{d}}(\lambda, z)$ & $\mu \mathrm{mol}$ quanta $\mathrm{m}^{-2} \cdot \mathrm{s}^{-1} \cdot \mathrm{nm}^{-1}$ \\
\hline Total downwelling irradiance & $E_{\mathrm{d}}(z)$ & $\mu$ mol quanta $\mathrm{m}^{-2} \cdot \mathrm{s}^{-1} \cdot \mathrm{nm}^{-1}$ \\
\hline Scalar irradiance & $E_{0}(\lambda, z)$ & $\mu$ mol quanta $\mathrm{m}^{-2} \cdot \mathrm{s}^{-1} \cdot \mathrm{nm}^{-1}$ \\
\hline Total scalar irradiance & $E_{0}(z)$ & $\mu$ mol quanta $\mathrm{m}^{-2} \cdot \mathrm{s}^{-1} \cdot \mathrm{nm}^{-1}$ \\
\hline Functional Group 1-Prochlorococcus (low light) & FG1 & $\mu \mathrm{M}$ or $\mu \mathrm{g} \mathrm{L}^{-1}$ \\
\hline Functional Group 2-Prochlorococcus (high light) & FG2 & $\mu \mathrm{M}$ or $\mu \mathrm{g} \mathrm{L}^{-1}$ \\
\hline Functional Group 3-Synechococcus & FG3 & $\mu \mathrm{M}$ or $\mu \mathrm{g} \mathrm{L}^{-1}$ \\
\hline Functional Group 4-Chromophycota (golden-browns) & FG4 & $\mu \mathrm{M}$ or $\mu \mathrm{g} \mathrm{\textrm {L } ^ { - 1 }}$ \\
\hline Downwelling diffuse attenuation coefficient & $K_{\mathrm{d}}(\lambda, z)$ & $\mathrm{m}^{-1}$ \\
\hline Reduction in absorption resulting from pigment packaging & Package effect & Unitless \\
\hline Actual carbon to chlorophyll $a$ ratio & $\theta$ & $\mu g \mathrm{C}: \mu \mathrm{g}$ chl $a$ \\
\hline Optimal light-limited carbon to chlorophyll $a$ ratio & $\theta_{\text {opt(II) }}$ & $\mu g$ C: $\mu g$ chl $a$ \\
\hline Optimal nutrient-limited carbon to chlorophyll $a$ ratio & $\theta_{\text {opt }(\mathrm{nl})}$ & $\mu g$ C: $\mu g$ chl $a$ \\
\hline Intercept of light-limited C:chl $a$ versus light function & $\theta_{0(11)}$ & $\mu g$ C: $\mu g$ chl $a$ \\
\hline Intercept of nutrient-limited C:chl $a$ versus light function & $\theta_{0(\mathrm{nl})}$ & $\mu g$ C: $\mu g$ chl $a$ \\
\hline Slope of light-limited C:chl $a$ a versus light function & slope $_{\theta(11)}$ & $\mu g$ C: $\mu g$ chl $a /\left(\mu\right.$ mol quanta $\left.\cdot \mathrm{m}^{-2} \cdot \mathrm{s}^{-1}\right)$ \\
\hline Slope of nutrient-limited C:chl $a$ versus light function & slope $_{\theta(\mathrm{nl})}$ & $\mu g$ C: $\mu g$ chl $a /\left[\mu \mathrm{M} \mathrm{C}(\mu \mathrm{M} \mathrm{N})^{-1}\right]$ \\
\hline Actual C:chl $a$ ratio & $R$ & $\mu g$ C: $\mu g$ chl $a$ \\
\hline C:chl $a$ ratio towards which phytoplankton strive & $R_{\mathrm{w}}$ & $\mu g$ C: $\mu g$ chl $a$ \\
\hline Average cosine of downwelling photons & $-\bar{\mu}_{\mathrm{d}}(\lambda, z)$ & Unitless \\
\hline Average cosine of downwelling photons from direct sunlight & $-\bar{\mu}_{\mathrm{dir}}\left(\lambda, 0^{-}\right)$ & Unitless \\
\hline Average cosine of downwelling photons from diffuse sunlight & $-\bar{\mu}_{\mathrm{dif}}\left(\lambda, 0^{-}\right)$ & Unitless \\
\hline Average cosine of downwelling photons from total sunlight & $-\bar{\mu}_{0}\left(\lambda, 0^{-}\right)$ & Unitless \\
\hline
\end{tabular}

tion) IOP or fluorescence data (see below). Several new spectrometer systems offer the potential to provide hyperspectral data in the near future. While these transformation approaches can be applied to measurements of the IOPs, care should be taken when applying them to apparent optical measurements that are sensitive to the geometrical structure of the light field. Utilization of these techniques will also be dependent on further improvements in extracting phytoplankton spectral absorption from the bulk optical signals. Finally, finding a universal global approach for discriminating all $\mathrm{HAB}$ species is a pipe-dream. The similarity-index approach that appears appropriate for blooms of $G$. breve will not be applicable to all species. For example, HAB species like Alexandrium often represent a minor subset of the total phytoplankton community; therefore, the optical signal will often be dominated by the other algal species present. Given this, techniques and approaches will need to be tailored to specific algal species of interest.
Scattering. Light scattering measurements show promise for detecting the concentration and size of particulate material present in seawater (Bricaud and Morel 1986, Stramski and Kiefer 1991, Stramski and Mobley 1997). Most often, the measurements are of the low-angle forward and perpendicular components of the particulate scattering (Trask et al. 1982). These approaches have been most often exploited by flow cytometry with the assumption that small cells had a smaller scattering signal (Perry et al. 1983, Olson et al. 1985, Ackleson and Spinrad 1988). The theory underlying the estimation of particle size from scattering characteristics is based on the Mie theory with anomalous diffraction approximation, whereby the angular distribution of scattered light is a function of particle size and the relative refractive index (Van der Hulst 1957, Bricaud et al. 1983, Morel and Bricaud 1986, Stramski and Kiefer 1991). Given this, caution must be used when relating scattering to cell size. For example, the refractive index can change by over $80 \%$ during a 12 
TABLE 3. Bio-Optical equations for one optically-based ecosystem model.

\begin{tabular}{|c|c|}
\hline$a_{\mathrm{t}}(\lambda, z)=a_{\text {water }}(\lambda, z)+a_{\mathrm{ph}(t)}(\lambda, z)+a_{\mathrm{CDOM}}(\lambda, z)$ & 7 \\
\hline$a_{\mathrm{ph}(t)}(\lambda, z)=\sum_{i=1}^{4} a_{\mathrm{ph}(t, i)}(\lambda, z)$ & 8 \\
\hline$a_{\mathrm{ph}(t, i)}(\lambda, z)=$ package effect $\cdot \sum_{j=1}^{7}\left(\right.$ pigments $\left._{j}\left[\mathrm{mg} \mathrm{m}^{-3}\right] \cdot a_{\mathrm{pig}(j)}^{*}\left[\mathrm{~m}^{2} \mathrm{mg}^{-1}\right]\right)$ & 9 \\
\hline$\theta_{\text {opt }(11, i)}=\theta_{0(11, i)}+\operatorname{slope}_{\theta(11, i)} \cdot E_{0}(z)$ & 10 \\
\hline$\theta_{\mathrm{opt}(\mathrm{nl}, i)}=\theta_{0(\mathrm{nl}, i)}+\operatorname{slope}_{\theta(\mathrm{nl}, i)} \cdot \mathrm{C}_{i}: \mathrm{N}_{i}$ & 11 \\
\hline$\frac{\partial R_{i}}{\partial t}=\mu_{r(i)} \cdot R_{\overline{\mathrm{w}}(i)}-R_{i}$ & 12 \\
\hline$R_{\mathrm{w}(i)}=\left[\max \left(\theta_{\mathrm{opt}(\mathrm{ll}, i)}, \theta_{\mathrm{opt}(\mathrm{nl}, i)}\right)\right]^{-1}$ & $13 \mathrm{a}$ \\
\hline$R_{i}=\theta_{i}^{-1}$ & $13 \mathrm{~b}$ \\
\hline$a_{\mathrm{CDOM}}(\lambda, z)=\sum_{i=1}^{2} a_{\mathrm{CDOC}(i)}(\lambda, z)$ & 14 \\
\hline$a_{\mathrm{CDOC}(i)}(410, z)=a_{\mathrm{CDOC}(i)}^{*}(410, z) \cdot \mathrm{CDOC}_{i}(z)$ & 15 \\
\hline$a_{\mathrm{CDOC}(i)}(\lambda, z)=a_{\mathrm{CDOC}(i)}(410, z) \cdot \exp [S \cdot(410-\lambda)]$ & 16 \\
\hline$b_{\mathrm{bt}}(\lambda, z)=\tilde{b}_{\mathrm{bw}} \cdot b_{\overline{\mathrm{w}}}(\lambda, z)+\tilde{b}_{\mathrm{bp}} \cdot b_{\mathrm{wp}}(\lambda, z)$ & 17 \\
\hline$b_{\mathrm{p}}(\lambda, z)=0.30[\operatorname{chl} a(z)]^{0.62} \cdot \frac{550}{\lambda}$ & 18 \\
\hline$\tilde{b}_{\mathrm{bp}} \cdot b_{\mathrm{p}}(\lambda, z)=0.30[\operatorname{chl} a(z)]^{0.62} \cdot\left[0.002+0.02\left(\frac{1}{2}-\frac{1}{4} \log [\operatorname{chl} a(z)]\right) \cdot \frac{550}{\lambda}\right]$ & 19 \\
\hline$K_{\mathrm{d}}(\lambda, z)=\left[a_{\mathrm{t}}(\lambda, z)+b_{\mathrm{bt}}(\lambda, z)\right] / \bar{\mu}_{\mathrm{d}}(\lambda, z)$ & 20 \\
\hline $\bar{\mu}_{0}\left(\lambda, 0^{-}\right)=\left[\bar{\mu}_{\mathrm{dir}}\left(\lambda, 0^{-}\right) \cdot E_{\mathrm{dir}}\left(\lambda, 0^{-}\right)+\bar{\mu}_{\mathrm{dif}}\left(\lambda, 0^{-}\right) \cdot E_{\mathrm{dif}}\left(\lambda, 0^{-}\right)\right] \cdot\left[E_{\mathrm{tot}}\left(\lambda, 0^{-}\right)\right]^{-1}$ & 21 \\
\hline$E_{\mathrm{d}}(\lambda, z)=E_{\mathrm{d}}\left(\lambda, 0^{-}\right) \cdot \exp \left[\int_{0^{-}} K_{\mathrm{d}}(\lambda, z) \mathrm{d} z\right]$ & 22 \\
\hline$E_{0}(\lambda, z)=E_{\mathrm{d}}(\lambda, z) \cdot\left[K_{\mathrm{d}}(\lambda, z) / a_{\mathrm{t}}(\lambda, z)\right]$ & 23 \\
\hline
\end{tabular}

$\mathrm{h}$ light cycle due to changes in cellular pigmentation and intracellular compounds (Stramski and Reynolds 1993, Reynolds et al. 1997). Furthermore, like absorption measurements, the bulk scattering signal reflects the additive contributions of the specific components present, requiring inversion algorithms to extract the relative contribution of the phytoplankton (Shifrin 1988).

More relevant to the remote-sensing applications (see below) is the backward scattered light. Roesler and McLeroy-Etheridge (1998) have hypothesized that spectral backscattering coefficients may be used to derive the modal size of surface water particulate material. This might suggest that when HABs are associated with dense surface accumulations of algal cells, this derived modal size might represent the population. Modal size, in combination with derived phytoplankton absorption (i.e. pigment composition) and geographic location can provide sufficient information to determine the class-specific taxonomy of the bloom. While their approach used backscattering spectra derived from surface reflectance and absorption measurements, new instrumentation for obtaining backscattering coefficients in situ holds promise (Maffione and Dana 1997). The major problem with this strategy is that it will be sen- sitive to variations in the refractive index and can be disproportionately impacted by the presence of small particles. Additionally, as blooms develop and reach stationary phase, cell break up and aggregation lead to increased dispersion in particle-size distribution and reduced confidence in the derived cell modal size.

Fluorescence. Stimulated fluorescence of chlorophyll $a$ has been widely used to provide an estimate of phytoplankton concentrations in the field. Standard chlorophyll $a$ fluorometers thus provide a bulk signature and will not be useful in discriminating between algal species. Fluorescence however will remain a central mapping tool for phytoplankton monitoring programs. The accuracy of the estimated phytoplankton concentration is compromised by the natural variability in the fluorescence yield (fluorescence per chlorophyll; Kiefer 1973, Cullen 1982, Falkowski and Kiefer 1985, Sosik et al. 1989, Marra 1997). This variability can be related to environmental conditions (light, nutrients, and/or temperature). This allows fluorescence to provide estimates of the physiological state of the phytoplankton if the appropriate type of fluorescence measurements is made (Butler 1978, Falkowski and Kolber 1993, Kolber and Falkowski 1993, Schofield et al. 1995). Thus, 
although not HAB-specific, fluorescence-based photosystem II quantum yield measurements will be key for describing the potential health of the phytoplankton population.

As described above, the spectral signature of phytoplankton can potentially be used to detect the presence of HAB species. A technique that is phytoplankton-specific, highly sensitive in dilute suspensions and can provide hyperspectral data on phytoplankton pigmentation is chlorophyll $a$ fluorescence excitation spectra (Yentsch and Yentsch 1979). The major advantage of these measurements is that the spectrum provides only the signature for the photosynthetic pigments and avoids the confounding signal of nonphotosynthetic pigments (Yentsch and Phinney 1985, Demmig et al. 1987, Maske and Haardt 1987, Schubert et al. 1994) that are present within both nonHAB and HAB species. These stimulated fluorescence spectra thus have sharper pigment shoulders than corresponding absorption measurements (Schofield et al. 1990, Grzymski et al. 1997, Johnsen et al. 1997), which would increase the power of any pattern-recognition algorithm. Submersible fixed-wavelength spectrofluorometers are available (Spectral Absorption Fluorescence Excitation Emission Meter, SAFIRE, Wetalbs Inc.), but to date do not have the spectral resolution required for pattern-recognition algorithms.

The significant presence of CDOM in coastal and inland waters often dominates bulk absorption. This can compromise the accuracy of empirical inversion approaches as described above. A possible means to circumvent this problem is to develop independent means to estimate the in situ concentration of CDOM. Recently, techniques have been developed to characterize $\mathrm{CDOM}$ using $\mathrm{UV}$ and/or visible light-induced CDOM fluorescence (Hoge and Swift 1981, Coble et al. 1990, Chen and Bada 1992, Green and Blough 1994, Vodacek et al. 1995, Ferrari et al. 1996, Nieke et al. 1997). Commercially available submersible instrumentation can measure UV/visible light-induced fluorescence, thereby providing information on the concentration of CDOM (Fig. $5 \mathrm{~A}$ ) or the absorption of CDOM when the variance in the quantum yield is negligible (Ferrari and Tassan 1991). Further data is required to determine to what degree these observed relationships are linear over an environmentally relevant range of concentrations and are robust in both time and space. An example of CDOM fluorescence within 1997 G. breve bloom is presented in Figure 5B. There are, however, several caveats for using fluorescence to describe CDOM. First, calibration and standardization between instrument systems are not trivial, requiring careful consideration of the quantum correction factors to be applied to the instrument signals (Coble et al. 1990). Discrimination of the form of CDOM from fluorescence will only be to a general level (see Fig. 5C that presents the CDOM for estuarine waters). For example, marine CDOM can be differen- tiated from terrestrial CDOM by its overall low fluorescence intensity and the few prominent shoulders in the blue wavelengths of light (Coble et al. 1990, Coble 1996). Finally, the choice of the appropriate excitation-emission wavelengths for CDOM fluorometers will vary depending on the field site, given that the high CDOM absorption in UV and visible wavelengths will significantly affect instrument performance (Fig. 5D).

\section{REMOTE SENSING}

Above water ocean color is determined primarily from the reflectance, defined as the ratio of the upward flux of light to downward flux of light incident on the ocean surface. Atmospheric effects aside, reflectance is a function of both the scattering and absorption properties within the water column. The relationship between reflectance and the IOPs can reasonably be described as the ratio of backscatter to absorption, such as

$$
R=G \frac{b_{b}(\lambda)}{a(\lambda)+b_{b}(\lambda)}
$$

where $G$ is a constant dependent on the angular distribution of the light field and the volume scattering coefficient (Gordon et al. 1975, Morel and Prieur 1977, Zaneveld 1982, 1995).

Several satellite and aircraft remote-sensing systems currently are in use, each having distinct spectral and spatial resolution (IOCCG 1999). The derived products from these systems include chlorophyll $a$ biomass, CDOM, sediment, IOPs, primary productivity, and potentially community classification (phycobilin and nonphycobilin-containing algae, Subramaniam et al. 1999a, b). These systems collect data over ecologically relevant spatial scales, and therefore provide a mechanism to scan for algal productivity "hotspots." Given this, they will be key to the mapping of phytoplankton dynamics and provide inputs to coupled biological/hydrodynamic models. Furthermore, semianalytical approaches to invert the reflectance spectra have been developed and show great promise for refining the interpretation of remotesensing data (Fischer and Doerffer 1987, Gordon et al. 1988, Doerffer and Fischer 1994, Lee et al. 1994, Roesler and Perry 1995, Garver and Siegel 1997).

The disadvantages of ocean color satellites include the confounding impact of clouds, the limit of detection to near-surface features, the lack of HAB-specific algorithms, the often degraded spatial resolution of the sensor, and the stringent embargoes of real-time data access for most users. For aircraft sensors, considerations include cost, impact of partial cloud cover, as well as corrections for sensor geometry and atmospheric signals. Real-time fullresolution data from these satellites is accessible via direct-broadcast satellite dishes, which will enable scientists to access the growing international constellation of satellites (Table 1). The real-time data from the full constellation of satellites will be critical 
to minimize site revisit intervals and potentially provide researchers coverage at different times on the same day for tracking phytoplankton plumes. Development of regional networks of these direct access satellite dish platforms will be critical to the scientific community, much analogous to the importance of the proliferation of High Resolution Picture Transmission (HRPT) satellite data-acquisition systems which revolutionized the utility and availability of AVHRR satellite data. Development of these systems will be strongly dependent on in-water validation studies.

\section{ECOSYSTEM MODELS}

With the ability to measure in-water optical properties and the promise of algorithms to separate them into individual optical constituents, comes the inevitable question-how will optical data be used to describe HABs? Optically based ecosystem models will be a key tool in providing a means to optimally interpolate to regions where in situ data is sparse (in both space and time), coordinating field sampling efforts, and providing a central component to any forecasting network.

The work by Riley $(1946,1947)$ on Geogres Bank is often acknowledged as the root for many modern coastal-ecosystem models. While the earliest models varied with time, the environmental complexity was necessarily simplified. The environmental complexity of the models has increased with the increase in computing power, and by the 1970 s, explicit descriptions of circulation patterns were included to describe the physical transport of phytoplankon populations (Walsh 1975, Wroblewski 1977). Ecosystem models in recent years have with varying degress of success simulated seasonal changes in both chlorophyll $a$ and/or nutrient fields (Walsh et al. 1989, 1991, Bissett et al. 1994, McClain et al. 1999). Most of the models are based on simplified food webs (Walsh et al. 1999) and thus do not explicitly consider the natural phytoplankton diversity despite the fact that community diversity significantly affects foodweb dynamics and biogeochemistry. Given this, current ecosystem models are still a long way from the more specialized need of predicting HABs.

For the purposes of this paper, we focus our discussion on a model being developed for mixed-phytoplankton communities with the caveats that: (1) any of the available models will require substantial modification for HAB detection; and (2) the described model represents one of many possible models currently under development by the oceanographic community. We have chosen this model as it is designed to utilize the optical signals as inputs for biological parameters, and thus, it could be collected using the optical systems described above. The Ecological Simulation (EcoSim) 1.0 model (Fig. 6) has simulated the seasonal succession of phytoplankton communities and changes in the optical properties in the Sargasso Sea (Bissett et al. 1999a, b). This model describes the temporal changes in the in situ optical constituents and the effects on water clarity and resulting feedbacks on the ecosystem (Tables 2 and 3).

The EcoSim model utilizes the spectral distribution of light energy, along with temperature and nutrients, to drive the growth of phytoplankton functional groups (FG) representing broad classes of the phytoplankton species. For past simulations of the Sargasso Sea, the functional groups consisted of FG1-Prochlorococcus (high chlorophyll b), FG2Prochlorococcus (low chlorophyll b), FG3-Synechococcus, and FG4-Chromophyta (chlorophyll $c$ containing). The intracellular chlorophyll $a$ concentrations of each functional group vary as a function of the light history and nutrient status of the group. Each functional group has its own unique set of accessory pigments, which vary as a function of the carbon to chlorophyll $a$ ratio. Absorption by phytoplankton (eq. 8) is the sum of absorption from each phytoplankton species modified by the package effect (Morel and Bricaud 1986, eq. 9). Each phytoplankton species can chromatically adapt to changes in total photon flux (eq. 10) and intracellular nutrient status (eq. 11) through changes in the cellular carbon to chlorophyll $a$ ratio. Changes in carbon to chlorophyll $a$ ratios, in turn, lead to changes in accessory pigment concentrations (equations not shown). The time rate of change of the carbon to chlorophyll $a$ ratio is a function of the growth rate of the individual phytoplankton groups (eqs. 12 and 13). Other optically important parameters (eq. 7) are also parameterized with the model (eqs. 14-16).

Light intensity just below the sea surface-atmosphere interface, $\operatorname{Ed}\left(\lambda, 0^{-}\right)$, can be derived using atmospheric radiative transfer models (Gregg and Carder 1990) influenced by the variable presence of clouds. The attenuation of light energy with increasing water depth is a function of the distribution of light energy, as well as the spectral absorption and scattering of the water (Fig. 6). The absorption and scattering properties of the ecosystem respond to changes in the downwelling solar energy through cellular growth, loss of biomass, changes in pigmentation, and photolysis of CDOM. Similar to absorption, scattering (eq. 17) is assumed to be a linear combination of the individual optical constituents. The equations for particulate scattering and backscattering (eqs. 17-19) are related to total chlorophyll $a$ concentration (Morel 1988). The diffuse attenuation coefficient $\left(K_{\mathrm{d}}\right)$ is linked to the IOPs via an estimation of the geometric structure of the downwelling light field (eq. 20, Fig. 7) (Sathyendranath and Platt 1988). This value at the sea surface is given by equation 21 (Morel 1988). It is modified with depth as a function of the total scattering to beam attenuation ratio. Thus, with an estimation of $K_{\mathrm{d}}$, downwelling irradiance can be attenuated (eq. 22) and total scalar irradiance approximated (eq. 23). Model simulations for the optical signa- 


\section{Propagating Light Through a Water Column}

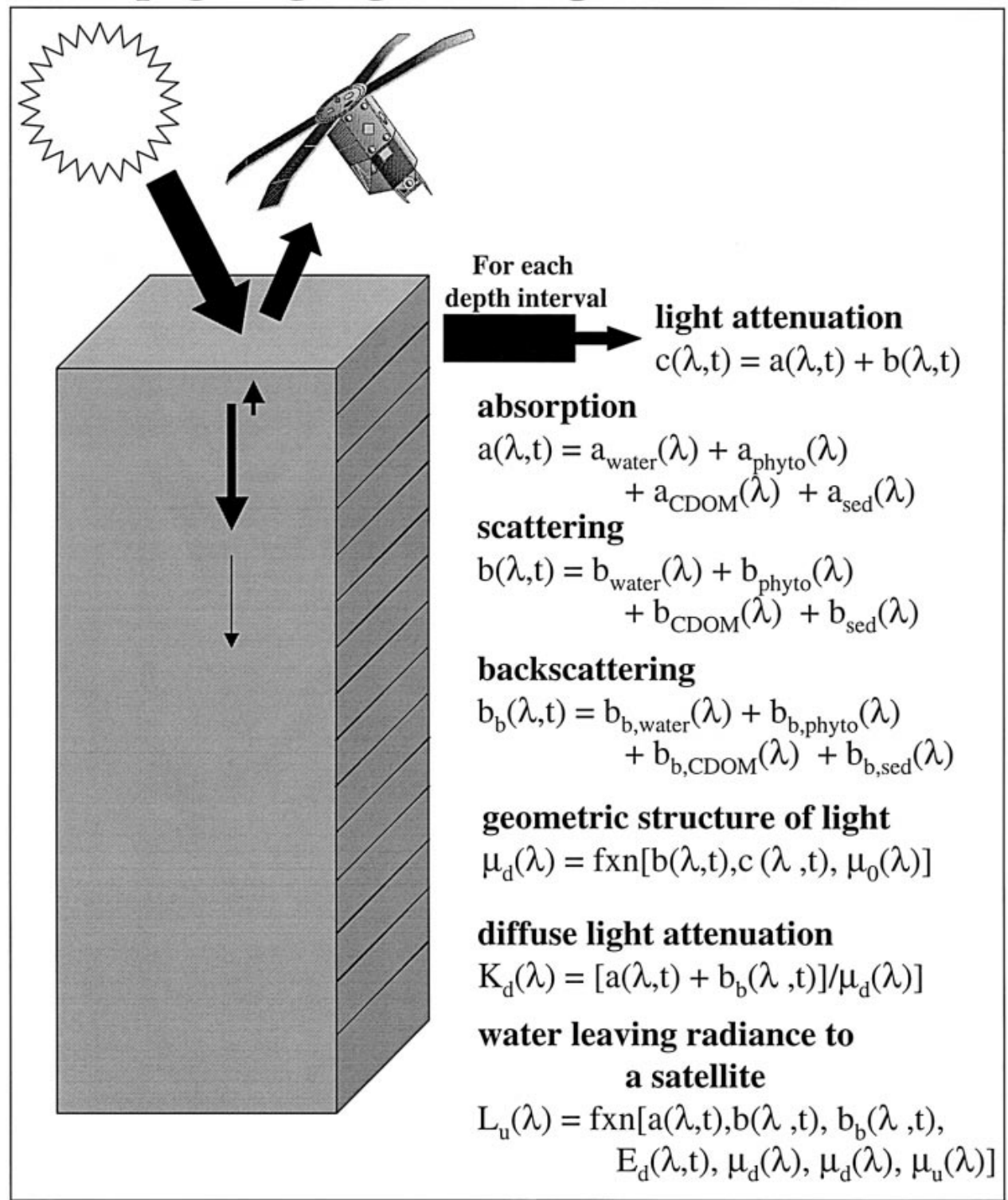

FIG. 7. Schematic view of Ecosim 1.0 bio-optical equations. Each layer in the filled column represents a layer in the EcoSim. The optical equations are solved for each of these layers as light propagates through the model domain.

tures of particulates, CDOM, and diffuse attenuation are presented in Figures 8 and 9. Model results agree well with measured in situ data (Fig. 9; Bissett et al. 1999a, b).

Although many of the approximations used in the model are simplistic, they are numerically efficient. This is important at this stage of model development. In the model, the equations for light propagation are limited to the downward direction. More accurate Radiative Transfer Models (RTM) that fully describe the geometric structure of the light field (Mobley 1994) exist; however, resolving the angular distribution of photons in EcoSim 1.0 would have increased the length of each simulation run from hours to tens of years. Although computer-process- ing speed has increased drastically in recent years, prediction of HABs will require three-dimensional ecological/optical/physical simulations, whose computational requirements would currently preclude the use of a complete RTM. Additionally, much more work is required in the field to rigorously test the predictions of the optical-simulation models.

Phytoplankton assemblages respond to an everchanging physical environment. The rise of a HAB species to bloom proportions is directly related to the past history and current status of the circulation patterns. Thus, the importance of accurately simulating the physical environment to future predictions of HAB outbreaks cannot be overemphasized. The EcoSim model was developed for an open 


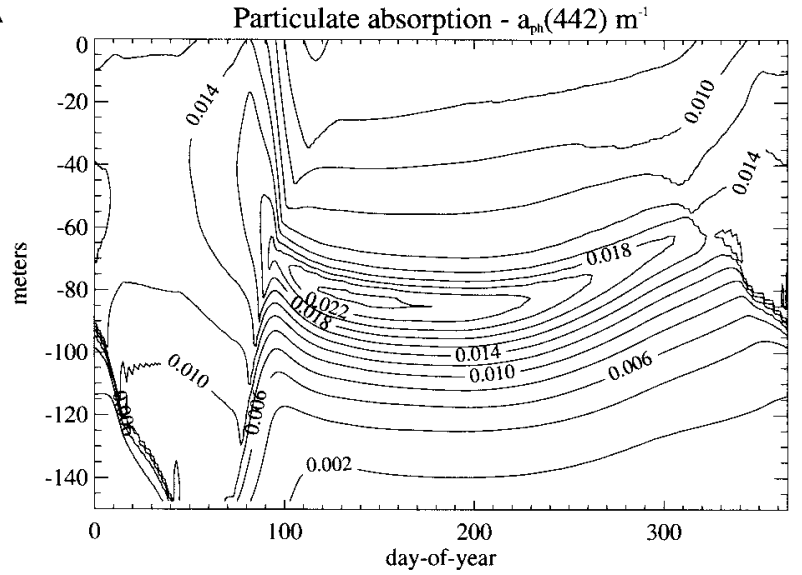

B

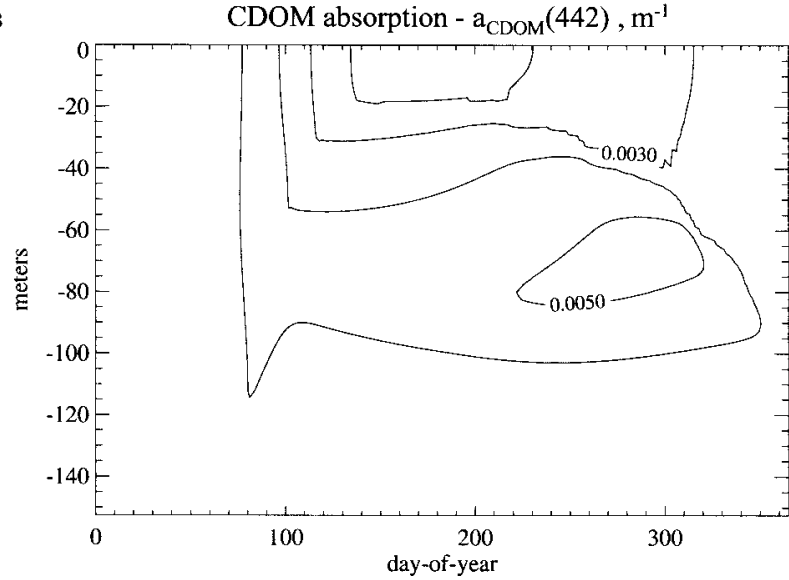

FIG. 8. Simulated seasonal variation in absorption at $442 \mathrm{~nm}$ for (A) particulates and (B) CDOM. Note that while the cycles are related they are not strictly correlated.

ocean study, where it was assumed that vertical mixing was the dominant physical process affecting the phytoplankton population. In this case, a one-dimensional turbulence closure scheme (Mellor and Yamada 1982, Chen et al. 1988, Walsh and Dieterle 1994) was used to simulate the daily changes in the surface-mixed layer. While this assumption may have been valid for Sargasso Sea, a one-dimensional assumption is unrealistic for a more complex coastal system wherein advective processes can dominate the physical environment. For these systems, a threedimensional simulation, for example, the Princeton Ocean Model (Blumberg and Mellor 1987) or the SCRUM model (Song and Haidvodgel 1994) that can resolve some of the complexities of the coastal physical environment will be required.

Finally, coupled biological-physical models are complex and nonlinear with numerous equilibrium states and instabilities (Lozano et al. 1996). Therefore, major consideration for the design of the model must also be related to the ecology of the HAB species and the relevant scales of interest (Franks 1997). Given that the competition between species reflects physiological responses to the physics which can operate over many scales (from turbulent scales to vertical and horizontal transport), this is not a trivial task. This requires the researcher to essentially decide to what degree small scale nonhydrodynamic processes will be required to be nested within larger scale circulation models. For example, how important is it for small-scale physics to provide an adequate population description of vertical migration (Kamykowski et al. 1994, 1998), and then how important is the vertical migration to larger scale bloom dynamics of the HAB species (Yanagi et al. 1995, Amano et al. 1998). Analogous decisions are also required in the temporal domain, that is, competition between species reflect the past and prevailing environmental conditions and the physiological capabilities of the individual species. Given this, how complex do dynamic physiological acclimation models need to be? A whole host of physiological models have been developed, all with varying degrees of complexity (Sakshaug et al. 1989, Geider 1993, Geider et al. 1996, 1998). Choosing the appropriate models essentially is a scaling problem that requires understanding of the processes that occur over different scales of time, space, and organizational complexity (Levin 1992). Although daunting, the increased understanding of the ecology of HAB species in nature [cf. Limnology and Oceanography vol. 42(5)], increases with computing power, and improved modeling capabilities do offer hope for robust models in the near (5-10 years) future.

\section{DATA ASSIMILATION AND FORECASTING SYSTEMS}

The scientific field of ocean forecasting is young, but quickly maturing due to significant advances in ocean-circulation modeling (Holland and Capotondi 1996) and the advent of data-assimilation methods adopted from the meteorology community (Dalay 1991). Data assimilation represents a procedure by which observations are used to constrain a dynamic numerical model. Historically, for meteorological predictions, this involves data being assimilated into a model by combining observed and modeled values to provide the initial conditions for the next model forecast run. The process of assimilating data is accomplished through a variety of methods. Early assimilation efforts in oceanography either inserted data directly into the circulation models (Holland and Hirschman 1972) or utilized least squares based assimilation schemes (Wunsch 1978, 1989). These approaches were replaced by the "nudging" technique developed by the meteorological community (Anthes 1974), wherein observational data were used only to adjust model solutions through the use of a relaxation term added to the dynamic model (Holland and Malanotte-Rizzoli 1989). These techniques advanced as assimilation methods began to utilize the uncertainty in both the models and observational data to refine the model adjustment.

Currently, suites of assimilation methods are available, all of which vary greatly in complexity and 


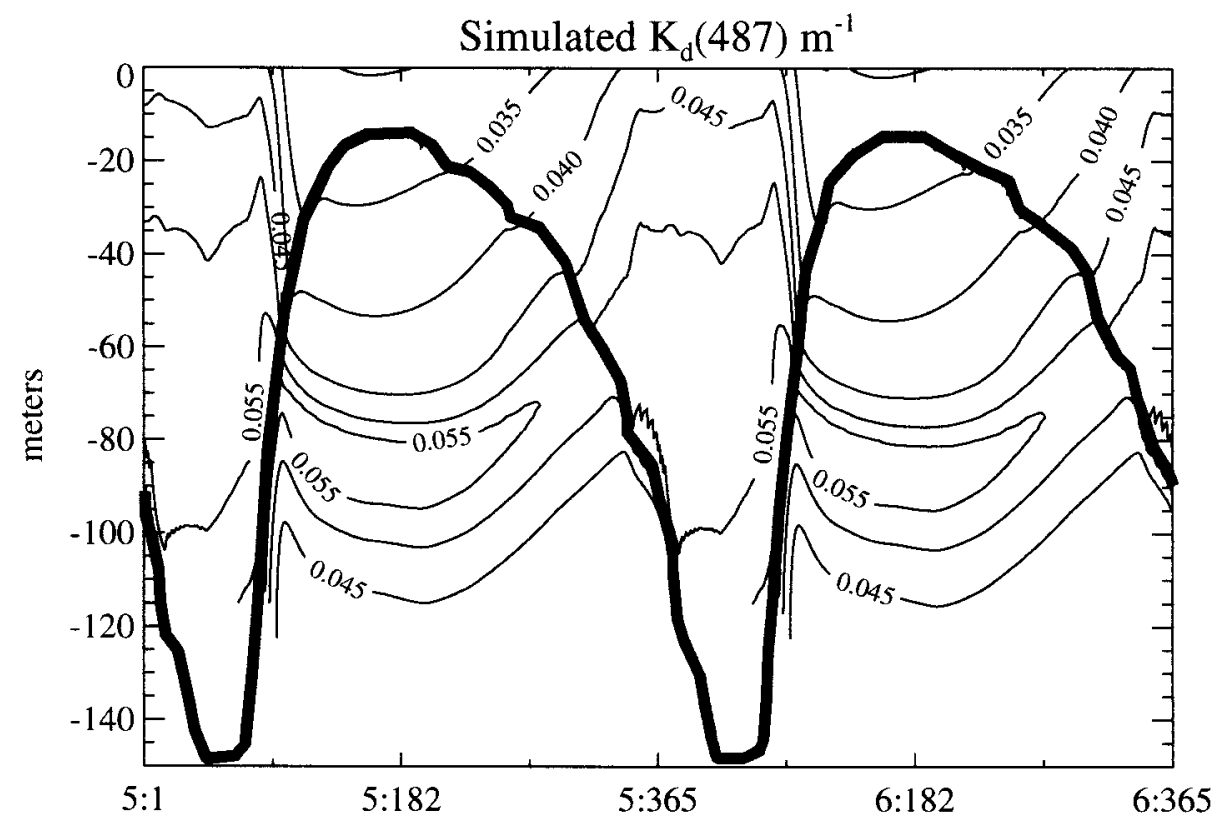

FIG. 9. (A) Simulated $K_{\mathrm{d}}(487)$ and (B) measured $K_{\mathrm{d}}(488)$. The measured $K_{\mathrm{d}}$ data was provided by Dr. D. Siegel, University of California at Santa Barbara. The bold black line is the mixed layer depth.

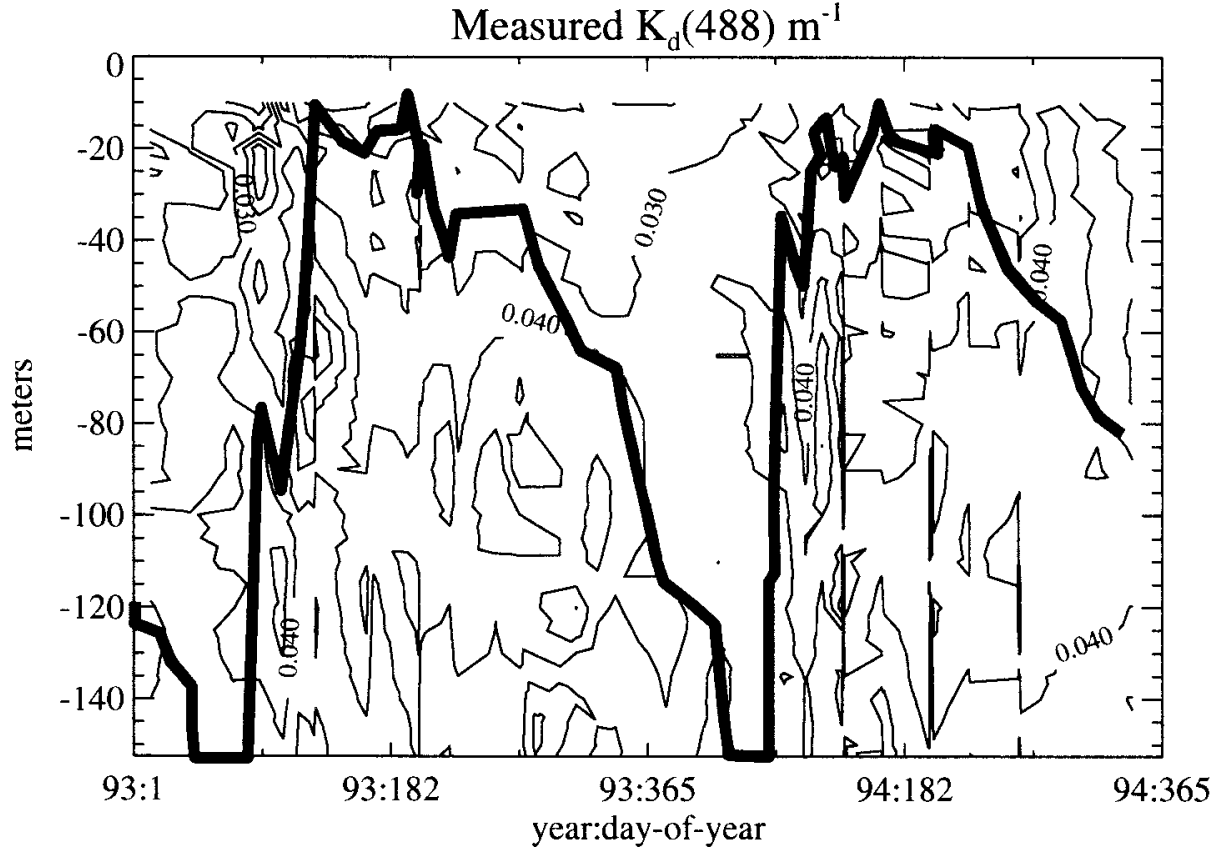

computational cost making them appropriate for different applications. The Optimal Interpolation (OI) method is a technique where model adjustment by observational data depends on the errors in the data, the dynamical constraints of the model, and the error estimate in the model solution (Bretherton et al. 1976, Dombrowsky and DeMey 1989, Robinson et al. 1989, Mellor and Ezer 1991). This approach has relatively low computational requirements making it appropriate for high-resolution forecast applications. More advanced schemes, such as the "Kalman filter/smoother" assimilation method (Kalman 1960), are computationally expensive,

which currently limits their use for complex models (Malanotte-Rizzoli and Tzipermann 1996), such as biological/hydrodynamic models that would be required for HAB forecasting applications. Another advanced assimilation scheme is the adjoint method, which is not appropriate for forecasting applications but is a powerful means to perform hindcast dynamical analyses. Such an approach will be useful for understanding the environmental conditions associated with algal bloom initiation from time-series data. Currently, several coupled physical-biological models have been constructed with data-assimilative methods (Ishizaka 1990, Fasham and Evans 1995, 


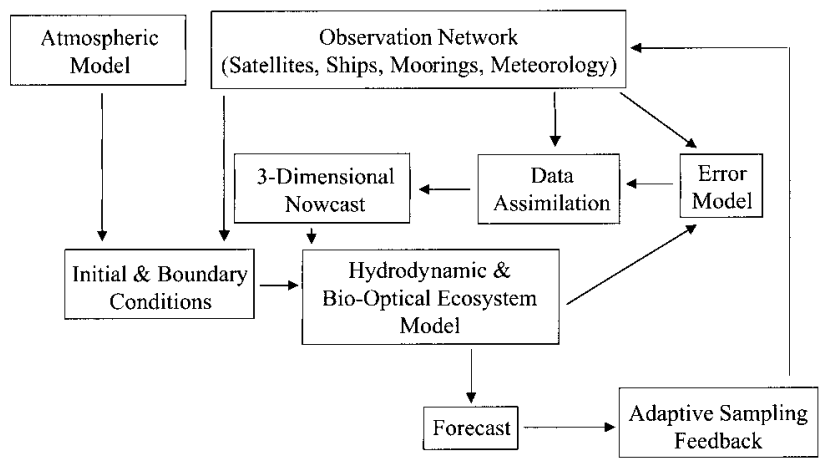

FIG. 10. Schematic for an ocean nowcast/forecast system allowing for adaptive sampling of events poorly sampled using traditional shipboard protocols. Schematic adapted from Glenn et al. 1998 .

Lawson et al. 1995, Matear 1995) providing a blueprint for future HAB data-assimilative models.

Coastal ocean forecasting networks generally work in a recursive mode (Glenn et al. 1998, Fig. 10). Initially, the data-assimilative model provides a nowcast that is moved forward in time by the circulation model driven by surface-boundary forcing. Surfaceboundary forcing is available through a variety of federal and defense weather prediction systems. The forecast cycle generally lasts for $2-4$ days after which the weather predictions become sufficiently coarse to compromise any predicted hydrographic or advection features. During the forecast cycle, additional field data are assimilated to constrain the model dynamics to provide improved nowcasts for the next set of ocean forecasts. To improve the quality of the nowcasts, adaptive sampling by ships and autonomous vehicles is initiated to collect subsurface data in specific regions within the forecast grid. Conversely, the forecasts/nowcasts provide an unprecedented opportunity for biologists to devise sampling strategies to characterize episodic events, which can play a disproportionately large role in structuring phytoplankton communities and which are poorly sampled using traditional protocols. Therefore, systems as described above will be critical in studying bloom initiation, maintenance, and senescence.

The utility of any forecasting system will vary with both the type and phase of the HAB bloom. For example, optical techniques are likely to have little success in detecting blooms during the earliest initiation phases of a bloom or in detecting HAB species that represent only a minor portion of the total phytoplankton community. These approaches will also not provide much success in predicting whether a particular bloom is toxic; however it will provide a means to structure monitoring efforts which can then utilize more powerful diagnostic tools. Given this, these approaches will provide researchers with a powerful suite of proactive tools for monitoring HAB populations in nature. For these tools to realize their full potential we recommend that research should focus on: (1) increasing the accuracy of methods to deconvolve the bulk IOPs into the individual constituents, with an emphasis on improving methods to derive phytoplankton spectra; (2) combining different optical measurements to increase the utility of multivariate pattern-recognition methods; (3) developing multiplatform observation networks to collect data in horizontal/vertical space over ecologically relevant scales; (4) refining ecosystem models to utilize the available optical data; (5) exploring and developing data-assimilation models in conjunction with physical oceanographers to create early generation biological-forecasting systems; (6) verifying and utilizing model forecasts for adaptive sampling of HAB phenomena; and (7) surviving the arduous period of trial and error.

Support was provided by numerous agencies including the Office of Naval Research's COMOP, HyCODE and CMO programs (N00014-97-0767, N0014-99-0196, N00014-98-10251), a National Ocean Partnership Award (N00014-97-1-1019), a USDA-NRI award (96-351010-3122), an EPA grant (R825243), a NASA grant (NAG5-7872), Florida DEP, and the William G. Selby and Marie Selby Foundation. Excellent and constructive reviews by two anonymous reviewers and John Cullen greatly improved this manuscript. Special thanks and a cold beer is owed to Scott Glenn. We are also very grateful to Trisha Bergmann, Kenneth Carder, Mike Crowley, Tom Fraser, Jennifer Patch, Robert Steward, and Bryan Vinyard. ECOHAB contribution number 6.

Ackelson, S. G. \& Spinrad, R. W. 1988. Size and refractive index of individual marine particulates: a flow cytometric approach. Appl. Opt. 27:1270-77.

Amano, K., Watanabe, M., Kohata, K. \& Harada, S. 1998. Conditions necessary for Chattonella antiqua red tide outbreaks. Limnol. Oceanogr. 43:117-28.

Anthes, R. A. 1974. Data assimilation and initialization of hurricane prediction models. J. Atmos. Sci. 31:701-19.

Bidigare, R. R., Morrow, J. H. \& Kiefer, D. A. 1989. Derivative analysis of spectral absorption by photosynthetic pigments in the western Sargasso Sea. J. Mar. Res. 47:323-41.

Bissett, W. P., Carder, K. L., Walsh, J. J. \& Dieterle, D. A. 1999a. Carbon cycling in the upper waters of the Sargasso Sea: II. Numerical simulation of apparent and inherent optical properties. Deep-Sea Res. 46:271-17.

Bissett, W. P., Meyers, M. B., Walsh, J. J. \& Muller-Karger, F. E. 1994. The effects of temporal variability of mixed layer depth on primary productivity around Bermuda. J. Geophys. Res. 99: 7539-53.

Bissett, W. P., Walsh J. J., Dieterle, D. A. \& Carder, K. L. 1999b. Carbon cycling in the upper waters of the Sargasso Sea: I. Numerical simulation of differential carbon and nitrogen fluxes. Deep-Sea Res. 46:205-69.

Blumberg, A. F. \& Mellor, G. L. 1987. A description of a three dimensional coastal ocean circulation model. In Heaps, $\mathrm{N}$. [Ed.] Three-dimensional Coastal Ocean Models, AGU, Washington DC, pp. 208-33.

Boss, E., Pegau, S., Zaneveld, J. R. V., Barnard, A. H. B. 1998. Spatial and temporal variability of absorption by dissolved material at a continental shelf. SPIE Ocean Optics XIV 2:4248.

Bretherton, F. P., Davis, R. E. \& Fandry, C. B. 1976. A technique for objective analysis and design of oceanographic experiments applied to MODE-73. Deep-Sea Res. 23:559-82.

Bricaud, A. \& Morel, A. 1986. Light attenuation and scttering by phytoplanktonic cells: A theorectical modeling. Appl. Opt. 25: 571-80.

Bricaud, A., Morel, A. \& Prieur, L. 1981. Absorption by dissolved organic matter of the sea (yellow substance) in the UV and visible domains. Limnol. Oceanogr. 26:45-53. 
1983. Optical efficiency factors of some phytoplankters. Limnol. Oceanogr. 28:816-73.

Bricaud, A. \& Stramski, D. 1990. Spectral absorption coefficients of living phytoplankton and nonalgal biogenous matter: a comparison between the Peru upwelling area and the Sargasso Sea. Limnol. Oceanogr. 35:562-82.

Bukata, R. P., Jerome, J. H., Kondratyev, K. Y. \& Pozdnyakov, D. V. 1995. Optical Properties and Remote Sensing of Inland and Coastal Waters. CRC Press, Boca Raton, 362 pp.

Butler, W. L. 1978. Energy distribution in the photochemical apparatus of photosynthesis. Annu. Rev. Plant Physiol. 29:34578.

Butler, W. L. \& Hopkins, D. W. 1970. An analysis of fourth derivative spectra. Photochem. Photobiol. 12:451-56.

Carder, K. L. \& Steward, R. G. 1985. A remote-sensing reflectance model of a red-tide dinoflagellate off west Florida. Limnol. Oceanogr. 30:286-98.

Carder, K. L., Steward, R. G., Harvey, G. R. \& Ortner, P. B. 1989. Marine humic and fulvic acids: Their effects on remote sensing of chlorophyll a. Limnol. Oceanogr. 34:68-81.

Carlson, R. D. \& Tindall, D. R. 1985. Distribution and periodicity of toxic dinoflagellates in the Virgin Islands. In Anderson, D. M. [Ed.] Toxic Dinoflagellates. Elsevier, New York, pp. 171-6.

Chen, R. F. \& Bada, J. L. 1992. The fluorescence of dissolved organic matter in seawater. Mar. Chem. 37:191-221.

Chen, D., Horrigan, S. G. \& Wang, D. P. 1988. The late summer vertical nutrient mixing in Long Island Sound. J. Mar. Res. $46: 753-70$

Cleveland, J. S. \& Perry, M. J. 1994. A model for partitioning particulate absorption into phytoplankton and detrital components. Deep-Sea Res. 41:197-21.

Coble, P. G. 1996. Characterization of marine and terrestrial DOM in seawater using excitation-emission matrix spectroscopy. Mar. Chem. 51:325-46.

Coble, P. C., Green, S., Blough, N. V. \& Gagosian, R. B. 1990 Characterization of dissolved organic matter in the Black Sea by fluorescence spectroscopy. Nature 348:432-35.

Cullen, J. J. 1982. The deep chlorophyll maximum: comparing profiles of chlorophyll a. Can. J. Fish. Aquat. Sci. 39:791-803.

Cullen, J. J., Ciotti, A. M. \& Lewis, M. R. 1997. Optical detection and assessment of algal blooms. Limnol. Oceanogr. 42:122339.

Dalay, R. 1991. Atmospheric Data Analysis. Cambridge University Press, Cambridge, 497 pp.

Demmig, B., Winter, K., Kruger, A., Czygan, F. C. 1987. Photoinhibition and zeaxanthin formation in intact leaves; a possible role of the xanthophyll cycle in the dissipation of excess light energy. Plant Physiol. 84:214-24.

Dickey, T. 1993. Sensors and systems for sampling/measuring ocean processes extending over nine orders of magnitude. Sea Tech. 34:47-55.

Doerffer, R. \& Fischer, J. 1994. Concentrations of chlorophyll, suspended matter, and gelbstoff in case II waters derived from satellite coastal zone color scanner data with inverse modeling methods. J. Geophy. Res. 99:7457-66.

Dombrowsky, E. \& DeMey, P. 1989. Continuous assimilation in an open domain of the Northeast Atlantic, part I: methodology and application to AthenA-88. J. Geophys. Res. 97:971931.

Duysens, I. N. M. 1956. The flattening of the absorption spectrum of suspensions, as compared to that of solutions. Biochim. Biophys. Acta. 19:1-12.

Falkowski, P. G. \& Kiefer, D. A. 1985. Chlorophyll a fluorescence and phytoplankton: Relationship to photosynthesis and biomass. J. Plankton Res. 7:715-31.

Falkowski, P. G. \& Kolber, Z. 1993. Estimation of phytoplankton photosynthesis by active fluorescence. ICES Mar. Sci. Symp. 197:92-103.

Fasham, M. J. R. \& Evans, G. T. 1995. The use of optimazation techniques to model marine ecosystems dynamics at the JGOFS station at $47^{\circ} \mathrm{N} 20^{\circ}$ W. Phil. Trans. Roy. Soc. 348:20309 .

Ferrari, G. M., Dowell, M. D., Grossi, S. \& Targa, C. 1996. Rela- tionship between the optical parameters of chromophoric dissolved organic matter and total concentration of dissolved organic carbon in the southern Baltic Sea region. Mar. Chem. $55: 299-16$.

Ferrari, G. M. \& Tassan, S. 1992. Evaluation of the influence of yellow substance absorption on the remote sensing of water quality in the Gulf of Naples. Inter. J. Rem. Sen. 13:2177-86.

Fischer, J. \& Doerffer, R. 1987. An inverse technique for remote detection of suspended matter, phytoplankton and yellow substance from CZCS measurements. Adv. Space Res. 7:21-26.

Franks, P. J. S. 1997. Models of harmful algal blooms. Limnol. Oceanogr. 42:1273-82.

Gallegos, C. L., Correll, D. L. \& Pierce, J. W. 1990. Modeling spectral diffuse attenuation, absorption, and scattering in a turbid estuary. Limnol. Oceanogr. 35:1486-502.

Garver, S. A. \& Siegel, D. A. 1997. Inherent optical property inversion of ocean color spectra and its biogeochemical interpretation: I. Time series from the Sargasso Sea. J. Geophys. Res. 102:18,607-25.

Garver, S. A., Siegel, D. A. \& Mitchell, G. B. 1994. Variability in near-surface particulate absorption spectra: what can an ocean color imager see? Limnol. Oceanogr. 39:1349-67.

Geider, R. J. 1993. Quantitative phytoplankton ecophysiology: Implications for primary production and phytoplankton growth. ICES Mar. Sci. Symp. 197:52-62.

Geider, R. J., MacIntyre, H. L. \& Kana, T. M. 1996. A dynamic model of photoadaptation in phytoplankton. Limnol. Oceanogr. 41:1-15.

1998. A dynamic regulatory model of phytoplankton acclimation to light, nutirents, and temperature. Limnol. Oceanogr. 43:679-94.

Glenn, S. M., Haidvogel, D. B., Schofield, O., von Alt, C. J. \& Levine, E. R. 1999. Coastal predictive skill experiments. Sea Tech. 39:63-69.

Gordon, H. R., Brown, O. B., Evans, R. H., Brown, J. W., Smith, R. C., Baker, K. S. \& Clark, D. K. 1988. A semianalytic radiance model of ocean color. J. Geophys. Res. 93:10,909-24.

Gordon, H. R., Brown, O. B. \& Jacobs, M. M. 1975. Computer relationships between the inherent and apparent optical properties of a flat homogenous ocean. Appl. Optics 14:41727.

Green, S. A. \& Blough, N. V. 1994. Optical absorption and fluorescence properties of chromophoric dissolved organic matter in natural waters. Limnol. Oceanogr. 39:1903-16.

Gregg, W. W. \& Carder, K. L. 1990. A simple spectral solar irradiance model for cloudless maritime atmospheres. Limnol. Oceanogr. 35:1657-75.

Grzymski, J., Johnsen, G. \& Sakshaug, E. 1997. The significance of intracellular self shading on the biooptical properties of brown, red, and green macroalgae. J. Phycol. 33:408-17.

Heil, C.A. 1986. Vertical migration of Ptycodiscus brevis (Davis) Steidinger. Masters thesis, University of South Florida, 118 pp.

Hoepffner, N. \& Sathyendranath, S. 1993. Determination of the major phytoplankton pigments from the absorption spectra of the particulate matter. J. Geophys. Res. 98:22,789-03.

Hoge, F. E. \& Swift, R. N. 1981. Airborne simultaneous spectroscopic detection of laser-induced water Raman backscatter and fluorescence from chlorophyll $a$ and other naturally occurring pigments. Appl. Opt. 20:3197-05.

Holland, W. R. \& Capotondi, A. 1996. Recent developments in prognostic ocean modeling. In Malanotte-Rizzoli, P. [Ed.] Modern Approaches to Data Assimilation in Ocean Modeling. Elsevier Science, Amsterdam, pp. 21-56.

Holland, W. R. \& Hirschman, A. D. 1972. A numerical calculation of the circulation in the North Atlantic ocean. J. Phys. Oceanogr. 2:336-54.

Holland, W. R. \& Malanotte-Rizzoli, P. 1989. Assimilation of altimeter data into an ocean circulation model: space versus time resolution studies. J. Phys. Oceanogr. 19:1507-34.

International Ocean-Colour Coordinating Group (IOCCG). 1999. Minimum Requirements for an Operational Ocean-colour Sensor for the Open Ocean. IOCCG-SCOR, Nova Scotia 1, 46 pp. 
Ishizaka, J. 1990. Coupling of coastal zone color scanner data to a physical-biological model of southeastern U.S. continetal shelf ecosystems. 3. Nutrient and phytoplankton fluzes and CZCS data assimilation. J. Geophys. Res. 95:20,201-12.

Jeffrey, S. W., Mantoura, R. F. C. \& Wright, S. W. 1997. Phytoplankton Pigments in Oceanography. United Nations Educational, Scientific, and Cultural Organization (UNESCO), Paris, $661 \mathrm{pp}$.

Jerlov, N. G. 1976. Marine Optics. Elsevier, New York, 1976.

Johnsen, G., Prézelin, B. B. \& Jovine, R. V. M. 1997. Fluorescence excitation spectra and light utilization in two red dinoflagellates. Limnol. Oceanogr. 42:1166-77.

Johnsen, G. \& Sakshaug, E. 1993. Bio-optical characteristics and photoadaptive responses in the toxic and bloom-forming dinoflagellates Gyrodinium aureolum, Gymnodinium galatheanum, and two strains of Prorocentrum minimum. J. Phycol. 29:627-42.

Johnsen, G., Samset, O., Granskog, L. \& Sakshaug, E. 1994. In vivo absorption characteristics in 10 classes of bloom-forming phytoplankton: taxonomic characteristics and responses to photoadaption by means of discriminant and HPLC analysis. Mar. Ecol. Prog. Ser. 105:149-57.

Kahru, M. \& Mitchell, B. G. 1998. Spectral reflectance and absorption of a massive red tide off southern California. J. Geophys. Res. 103:21,601-10.

Kalle, K. 1966. The problem of the gelbstoff in the sea. Oceanogr. Mar. Biol. Rev. 4:91-104.

Kalman, R. E. 1960. A new approach to linear filtering and prediction problems. J. Basic Eng. 83D:95-108.

Kamykowski, D., Milligan, E. J. \& Reed, R. E. 1998. Biochemical relationship with the orientation of the autotrophic dinoflagellate Gymnodinium breve under nutrient replete conditions. Mar. Ecol. Prog. Ser. 167:105-17.

Kamykowski, D., Yamzaki, H. \& Janowitz, G. S. 1994. A Langrangian models of phytoplankton photosynthetic response in the upper mixed layer. J. Plankton Res. 16:1059-69.

Kamykowski, D., Yamzaki, H., Yamzaki, A. K. \& Kirkpatrick, G. J. 1998. A comparison of how different orientation behaviors influence dinoflagellate trajectories and photoresponses in turbulent water columns. In Anderson, D. M., Cembella, A. D. \& Hallengraef, G. M. [Eds.] Physiological Ecology of Harmful Algal Blooms. Springer-Verlag, Berlin, pp. 581-99.

Kiefer, D. A. 1973. Chlorophyll $a$ fluorescence in marine centric diatoms: responses of chloroplasts to light and nutrient stress. Mar. Biol. 23:39-46.

Kiefer, D. A. \& Soohoo, J. B. 1982. Spectral absorption by marine particles of coastal waters of Baja California. Limnol. Oceanogr. 27:492-99.

Kirk, J. T. O. 1977. Use of a quanta meter to measure attenuation and underwater reflectance of photosynthetically active radiation in some inland and coastal southeastern Australian waters. Aust. J. Mar. Fresh. Res. 28:9-21.

- 1994. Light and Photosynthesis in Aquatic Ecosystems. Cambridge University Press, Cambridge, 509 pp.

Kolber, Z. \& Falkowski, P. G. 1993. Use of active fluorescence to estimate phytoplankton photosynthesis in situ. Limnol. Oceanogr. 38:1646-65.

Lawrence, J. 1994. Introduction to Neural Networks. California Scientific Software Press. Nevada City, 347 pp.

Lawson, L. M., Spitz, Y. H., Hofmann, E E. \& Long, R. B. 1995. A data assimilation technique applied to a predator-prey model. Bull. Math. Biol. 57:593-17.

Lee, Z., Carder, K. L., Hawes, S. K., Steward, R. G., Peacock, T. G. \& Davis, C. O. 1994. Model for the interpretation of hyperspectral remote sensing reflectance. Appl. Opt. 33:572132.

Levin, S. A. 1992. The problem of pattern and scale in ecology. Ecologia 73:1943-67.

Lozano, C. J., Robinson, A. R., Arango, H. G., Gangopadhyay, A., Sloan, Q., Haley, P. J., Anderson, L. \& Lesile, W. 1996. An interdisciplinary ocean prediction system: Assimilation strategies and structured data models. In Malanotte-Rizzoli, P. [Ed.] Modern Approaches to Data Assimilation in Ocean Modeling. Elsevier Science, Amsterdam, pp. 413-52.
Maffione, R. A. \& Dana, D. R. 1997. Instruments and methods for measuring the backscatter-scattering coefficient in ocean waters. Appl. Opt. 36:6057-67.

Malanotte-Rizzoli, P. \& Tzipermann, E. 1996. The oceanographic data assimilation problem: Overview, motivation and purposes. In Malanotte-Rizzoli, P. [Ed.] Modern Approaches to Data Assimilation in Ocean Modeling. Elsevier Science, Amsterdam, pp. $3-17$.

Marra, J. 1997. Analysis of diel variability in chlorophyll fluorescence. J. Mar. Res. 55:767-84.

Maske, H. \& Haardt, H. 1987. Quantitiative in vivo absorption spectra of phytoplankton: Detrital absorption and comparison with fluorescence excitation spectra. Limnol. Oceanogr. 32: $620-33$

Matear, R. J. 1995. Parameter optimization and analysis of ecosystem models using simulated annealing: a case study at Station P. J. Mar. Res. 53:571-07.

McClain, C. R., Murtuguddle, R. \& Signorini, S. 1999. A simulation of biological processes in the equatorial Pacific Warm Pool at $165^{\circ}$ E. J. Geophy. Res. 104:18,305-22.

McFarren, E. F., Tanabe, H., Silva, F. J., Wilson, W. B., Campbell, J. E. \& Lewis, K. H. 1965. The occurrence of a ciguatera-like poison in oysters, clams and Gymnodinium breve cultures. Toxicon. 3:111-23.

Mellor, G. L. \& Ezer, T. 1991. A Gulf Stream model and an altimeter assimilation scheme. J. Geophys. Res. 96:8779-95.

Mellor, G. L. \& Yamada, T. 1982. Development of a turbulence closure model for geophysical fluid problems. Rev. Geophys. Spa. Phy. 20:851-75.

Millie, D. F., Kirkpatrick, G. J. \& Vinyard, B. T. 1995. Relating photosynthetic pigments and in vivo optical density spectra to irradiance for the Florida red-tide dinoflagellate Gymnodinium breve. Mar. Ecol. Prog. Ser. 120:65-75.

Millie, D. F., Schofield, O., Kirkpatrick, G. J., Johnsen, G., Tester, P. A. \& Vinyard, B. T. 1997. Phytoplankton pigments and absorption spectra as potential 'Biomarkers' for harmful algal blooms: a case study of the Florida red-tide dinoflagellate, Gymnodinium breve. Limnol. Oceanogr. 42:1240-51.

Mobley, C. D. 1994. Light and Water Radiative Transfer in Natural Waters. Academic Press, San Diego, 591 pp.

Mooers, N. K. 1999. Coastal Ocean Prediction. Coastal and Estuarine Studies vol. 56. American Geophysical Union, Washington D.C., 526 pp.

Morel, A. 1988. Optical modeling of the upper ocean in relation to its biogenous matter content (Case I waters). J. Geophys. Res. 93:10,749-68.

Morel, A. \& Bricaud, A. 1986. Inherent optical properties of algal cells including picoplankton: Theoretical and experimental results. In Platt, T. \& Li, W. K. W. [Eds.] Photosynthetic Picoplankton. Canadian Bulletin on Fisheries and Aquatic Science, pp. 521-59.

Morel, A. \& Prieur, L. 1997. Analysis of variations in ocean color. Limnol. Oceanogr. 22:709-22.

Morrow, J. H., Chamberlin, W. S. \& Keifer D. A. 1989. A twocomponent description of spectral absorption by marine particles. Limnol. Oceanogr. 34:1500-09.

Nieke, B., Reuter, R., Heuermann, R., Wang, H., Babin, M. \& Therriault, J. C. 1997. Light absorption and fluorescence properties of chromophoric dissolved organic matter (CDOM), in the St. Lawrence Estuary (Case 2 waters). Cont. Shelf Res. 17:235-52.

Olson, R. J., Vaulot, D. \& Chisholm, S. W. 1985. Marine phytoplankton distributions measured using shipboard flow cytometry. Deep-Sea Res. 32:1273-80.

Pegau, S. W., Cleveland, J. S., Doss, W., Kennedy, D. W., Maffione, R. A., Mueller, J. L., Stone, R., Trees, C. C., Weidemann, A. D., Wells, W. H. \& Zaneveld, J. R. V. 1995. A comparison of methods for the measurement of the absorption coefficient in natural waters. J. Geophys. Res. 100:13,201-21.

Perry, M. J., Phinney, D. A., Pomponi, S. A., Spinrad, R. W., Wood, M., Yentsch, C. S. \& Zahuranec, B. J. 1983. Flow cytometry and cell sorting: A technique for analysis and sorting of aquatic particles. Limnol. Oceanogr. 28:1275-80. 
Pierce, R. H., Henry, M. S., Proffitt, L. S. \& Hasbrouk, P. A. 1990. Red tide toxin (brevetoxin) enrichment in marine aerosol. In Graneli, E., Sundstrom, E. B., Edler, L. \& Anderson, D. M. [Eds.] Toxic Marine Phytoplankton. Elsevier, New York, pp. 397-402.

Prézelin, B. B. \& Boczar, B. A. 1986. Molecular bases of cell absorption and fluorescence in phytoplankton: potential applications to studies in optical oceanography. Prog. Phycol. Res. 4:350-64.

Reynolds, R. A., Stramski, D. \& Kiefer, D. A. 1997. The effect of nitrogen-limitation on the absorption and scattering properties of the marine diatom Thalassiosira pseudonana. Limnol. Oceanogr. 42:881-92.

Riley, C. M., Holt, S. A., Holt, G. J., Buskey, E. J. \& Arnold, C. R. 1989. Mortality of larval red drum (Sciaenops ocellatus) associated with a Ptychodiscus brevis red tide. Contrib. Mar. Sci. 31:137-46.

Riley, G. A. 1946. Factors controlling phytoplankton populations on Geogres Bank. J. Mar. Res. 6:54-73.

- 1947. A theorectical analysis of the zooplankton population on Geogres Bank. J. Mar. Res. 6:104-11.

Robinson, A. R, Spall, M. A., Walstad, L. F. \& Leslie, W. G. 1989. Data assimilation and dynamical interpolation in Gulfcast experiments. Dyn. Atmos. Oceans 13:269-30.

Roesler, C. S. 1998. Theoretical and experimental approaches to improve the accuracy of particulate absorption coefficients derived from the quantitative filter technique. Limnol. Oceanogr. 43:1649-60.

Roesler, C. S. \& McLeroy-Etheridge, S. L. 1998. Remote detection of harmful algal blooms. SPIE Ocean Optics XIV 1:11728.

Roesler, C. S. \& Perry, M. J. 1995. In situ phytoplankton absorption, fluorescence emission, and particulate backscattering spectra determined from reflectance. J. Geophys. Res. 100: 13,279-94

Roesler, C. S., Perry, M. J. \& Carder, K. L. 1989. Modeling in situ phytoplankton absorption from total absorption spectra in productive inland marine waters. Limnol. Oceanogr. 34:151023.

Roesler, C. S. \& Zaneveld, J. R. V. 1994. High resolution vertical profiles of spectral absorption, attenuation, and scattering coefficients in highly stratified waters. Proc. Soc. Photo-Opt. Instrum. Engineer. 2258:309-19.

Sakshaug, E., Andersen, K. \& Kiefer, D. A. 1989. A steady state description of growth and light absorption in marine planktonic diatom Skeletonema costatum. Limnol. Oceanogr. 34: 198-205.

Sathyendranath, S. \& Platt, T. 1988. The spectral irradiance field at the surface and in the interior of the ocean: A model for applications in oceanography and remote sensing. J. Geophys. Res. 93:9270-80.

Schofield, O., Bergmann, T., Grzymski, J. \& Glenn, S. 1999. Spectral fluorescence and inherent optical properties during upwelling events off the coast of New Jersey. SPIE Ocean Optics XIV 3:60-67.

Schofield, O., Bidigare, R. R. \& Prézelin, B. B. 1990. Spectral photosynthesis, quantum yield and bluegreen light enhancement of productivity rates in the diatom Chaetoceros gracile and the prymnesiophyte Emiliania huxleyi. Mar. Ecol. Prog. Ser. 64: 175-86.

Schofield, O., Prézelin, B. B. \& Kroon, B. M. A. 1995. Impact of ultraviolet-B radiation on photosystem II activity and its relationship to the inhibition of carbon fixation rates for Antarctic ice algae communities. J. Phycol. 31:703-15.

Schubert, H., Kroon, B. M. A. \& Matthijs, H. C. P. 1994. In vivo manipulation of the xanthophyll cycle and the role of zeaxanthin in the protection against photodamage in the green alga, Chlorella pyrenoidosa. J. Biol. Chem. 269:7267-72.

Schulman, L. S., Roszell, L. E., Mende, T. J., King, R. W. \& Baden, D. G. 1990. A new polyether toxin from Florida red tide dinoflagellate Ptychodiscus brevis. In Graneli, E., Sundstrom, E. B., Edler, L. \& Anderson D. M. [Eds.] Toxic Marine Phytoplankton. Elsevier. New York, pp. 407-12.
Shifrin, K. S. 1988. Physical optics of ocean water. American Institute of Physics, New York, 285 pp.

Smith, C. M. \& Alberte, R. S. 1994. Characterization of in vivo absorption features of chlorophyte, phaeophyte, and rhodophyte algal species. Mar. Biol. 118:511-21.

Smith, R. S., Brown, O. B., Hoge, F. E., Baker, K. S., Evans, R. H., Swift, R. N. \& Esaias, W. E. 1987. Multiplatform sampling (ship, aircraft, and satellite) of a Gulf Stream warm core ring. Appl. Opt. 26:2068-81.

Song, Y. \& Haidvodgel, D. B. 1994. A semi-implicit ocean circulation model using a generalized topography-following coordinate system. J. Comp. Phys. 115:228-44.

Sosik, H. M., Chisholm, S. W. \& Olson, R. J. 1989. Chlorophyll fluorescence from single cells: interpretation of flow cytometric signals. Limnol. Oceanogr. 34:1749-61.

Steidinger, K. A. 1975. Implications of dinoflagellate life cycles on initiation of Gymnodinium breve red tides. Environ. Lett. 9 129-39.

Stramski, D. \& Kiefer, D. A. 1991. Light scattering by microorganisms in the open ocean. Prog. Oceanogr. 28:250-68.

Stramski, D. \& Mobley, C. D. 1997. Effects of microbial particles on oceanic optics: A databased of single-particle optical properties. Limnol. Oceanogr. 42:538-49.

Stramski, D. \& Reynolds, R. A. 1993. Diel variations in the optical properties of a marine diatom. Limnol. Oceanogr. 38:1347-64.

Subramaniam, A., Carpenter, E. J. \& Falkowski, P. G. 1999a. Optical properties of the marine diazotrophic cyanobacteria Trichodesmium spp.: II-A reflectance model for remote sensing. Limnol. Oceanogr. 44:608-17.

Subramaniam, A., Carpenter, E. J., Karentz, D. \& Falkowski, P. G. 1999b. Bio-optical properties of the marine diazotrophic cyanobacteria Trichodesium spp.: I-Absorption and photosynthetic action spectra. Limnol. Oceanogr. 44:618-27.

Trainor, V. L. \& Baden, D. G. 1990. Enzyme immunoassay of brevetoxins. In Graneli, E., Sundstrom, E. B., Edler, L. \& Anderson, D. M. [Eds.] Toxic Marine Phytoplankton. Elsevier, New York, pp. 430-35.

Trask, B. J., van den Engh, G. L. \& Elgershuizen, J. H. B. W. 1982. Analysis of phytoplankton by flow cytometry. Cytometry 2:258 64.

Van der Hulst, H. C. 1957. Light Scattering by Small Particles. John Wiley \& Sons, New York, 470 pp.

Varela, R. A., Figuerias, F. G., Arbones, B. \& Augutí, S. 1998. Determining the contribution of pigments and the nonalgal fractions to total absorption: toward an imporved algorithm. Limnol. Oceanogr. 43:449-57.

Vernet, M., Neori, A. \& Haxo, F. T. 1989. Spectral properties and photosynthetic action spectra in a red-tide population of Prorocentrum micans and Gonyaulax polyhedra. Mar. Biol. 103: 365-71.

Vodacek, A., Hoge, F. E., Swift, R. N., Yungel, J. K., Peltzer, E. T. \& Blough, N. V. 1995. The use of in situ and airborne fluorescence measurements to determine UV absorption coefficients and DOC concentrations in surface waters. Limnol. Oceanogr. 40:411-15.

Walsh, J. J. 1975. A spatial simulation model of the Peru upwelling ecosystem. Deep-Sea Res. 21:201-36.

Walsh, J. J. \& Dieterle, D. A. 1994. $\mathrm{CO}_{2}$ cycling in the coastal ocean. I-A numerical analysis of the southeastern Bering Sea with applications to the Chukchi Sea and the northern Gulf of Mexico. Prog. Oceanogr. 34:335-92.

Walsh, J. J., Dieterle, D. A., Meyers, M. B. \& Müller-Karger, F. E. 1989. Nitrogen exchange at the continental margin: A numerical study of the Gulf of Mexico. Progr. Oceanogr. 23:245301.

Walsh, J. J., Dieterle, D. A., Muller-Karger, F. E., Bohrer, R., Bissett, P. W., Varela, R. J., Aparicio, R., Diaz, R., Thunell, R., Taylor, G. T., Scranton, M. I., Fanning, K. A. \& Peltzer, T. 1999. Simulation of carbon-nitrogen cycling during spring upwelling in the Cariaco Basin. J. Geophys. Res. 104:7807-26.

Walsh, J. J., Dieterle, D. A. \& Pribble, J. R. 1991. Organic debris on the continental margins: a simulation analysis of source and fate. Deep-Sea Res. 38:805-28. 
Wroblewski, J. S. 1977. A model of phytoplankton plume formation during variable Oregon upwelling. J. Mar. Res. 35: 357-94.

Wunsch, C. I. 1978. The general circulation of the North Atlantic west of $50^{\circ} \mathrm{W}$ determined from inverse methods. Rev. Geophys. Space Phys. 16:583-620.

1989. Tracer inverse problems. In Anderson, D. L. T. \& Willebrand, J. [Eds.] Oceanic Circulation Models: Combining Data and Dynamics. Kluwer Academic Press, Dordrecht, pp. $1-78$.

Yanagi, T., Yamamoto, T., Koizumi, Y., Ikeda, T., Kamizono, M. \& Tamoi, H. 1995. A numerical simulation of red tide formation. J. Mar. Syst. 6:269-85.

Yentsch, C. S. \& Phinney, D. A. 1985. Spectral fluorescence: an ataxonomic too for studying the structure of phytoplankton populations. J. Plankton Res. 7:617-32.

Yentsch, C. S. \& Yentsch, C. M. 1979. Fluorescence spectral signatures: The characterization of phytoplankton populations by the use of excitation and emission spectra. J. Mar. Res. 37: 471-83.

Zaneveld, J. R. V. 1982. Remotely sensed reflectance and its dependence on vertical structure: a theoretical derivation. Appl. Optics 21:4146-50.

1995. A theoretical derivation of the dependence of the remotely sensed reflectance of the ocean on the inherent optical properties. J. Geophys. Res. 100:13,135-42.

Zaneveld, J. R. V., Kitchen, J. C. \& Moore, C. 1994. Scattering correction of reflecting tube absorption meter. Proc. Soc. Photo-Opt. Instrum. Engineer. 2258:44-55. 